\title{
Impact of the atmospheric climate modes on Mediterranean sea level variability
}

ARTICLE in GLOBAL AND PLANETARY CHANGE · JULY 2014

Impact Factor: 3.71 · DOI: 10.1016/j.gloplacha.2014.03.007

DOWNLOADS

21

6 AUTHORS, INCLUDING:

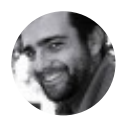

Adrián Martínez-Asensio

University of the Balearic Islands

5 PUBLICATIONS 1 CITATION

SEE PROFILE

Gabriel Jordà

University of the Balearic Islands

65 PUBLICATIONS 370 CITATIONS

SEE PROFILE
VIEWS

48
Marta Marcos

Mediterranean Institute for Advanced Studie...

93 PUBLICATIONS 826 CITATIONS

SEE PROFILE 
2 Impact of the atmospheric climate modes on Mediterranean sea level 3 variability

7 Josey $^{2}$, Gabriel Jordà ${ }^{1}$

$8{ }^{1}$ IMEDEA(UIB-CSIC), Spain

$9 \quad{ }^{2}$ National Oceanography Center, Southampton, UK

10 *Corresponding author: adrian.martinez@uib.es

\section{Abstract}

15 The relationships of Mediterranean sea level, its atmospherically driven and thermosteric 16 components with the large scale atmospheric modes over the North Atlantic and Europe 17 are explored and quantified. The modes considered are the North Atlantic Oscillation 18 (NAO), the East Atlantic pattern (EA), the Scandinavian pattern (SCAN) and the East 19 Atlantic/Western Russian (EA/WR). The influence of each mode changes between winter 20 and summer. During winter the NAO is the major mode impacting winter Mediterranean 21 sea level (accounting for $83 \%$ of the variance) with SCAN being the second (56\%) mode 22 in importance. Both NAO and SCAN effects are partly due to direct atmospheric forcing 23 of sea level through wind and pressure changes. However NAO and SCAN are correlated 24 with each other during winter and they explain the same part of variability. The EA/WR 25 also affects the atmospheric sea level component in winter (13\%), acting through 26 atmospheric pressure patterns. In winter, the thermosteric contribution is correlated with 27 the SCAN in parts of the Eastern Mediterranean (9\%). The rate of change of the 28 thermosteric component in winter is correlated with the EA (24\%). During the summer 29 season, the sea level variance is much reduced and the impact of the large scale modes is 30 in most parts of the Mediterranean Sea non significant.

32 Keywords: Mediterranean, climate indices, sea level variability 


\section{Introduction}

35 Sea level integrates changes in the thermohaline characteristics of the ocean waters due to

36 heat fluxes and water advection, changes in the ocean mass either due to redistribution of

37 water in response to the atmospheric mechanical forcing or due to the addition or removal

38 of water from the land and the criosphere, and, depending on the reference system, may

39 also include land movements and changes in the oceanic configuration. With the

40 exception of land movements and changes in the shape of the oceanic basin the other two

41 sea level components (thermohaline and mass) are influenced by the large scale

42 atmospheric climate modes through their effect on atmospheric pressure gradients, wind,

43 heat and freshwater fluxes and changes in the oceanic circulation.

44 Mediterranean sea level rise observed in the longest tide gauges during the last century

45 (1.1-1.3 mm/year) was significantly lower than the global rate $(1.5-1.9 \mathrm{~mm} / \mathrm{year})$

46 (Tsimplis \& Baker 2000; Church and White, 2011). An increase of the averaged

47 atmospheric pressure over the basin during the period 1960-1990 resulted in negative

48 trends of Mediterranean sea level, while in the Atlantic stations the positive trends were

49 lower for this period (Tsimplis \& Baker 2000; Tsimplis \& Josey 2001). Global and

50 Mediterranean rates significantly increased during the period 1993-2010 (Church and

51 White, 2011; Cazenave et al.2001; Fenoglio-Marc 2001).

52 For the Mediterranean Sea, the North Atlantic Oscillation (NAO) is known to affect,

53 primarily, winter sea level variability (Tsimplis and Josey, 2001; Gomis et al 2008;

54 Tsimplis and Shaw, 2008; Criado-Aldeanueva et al., 2008; Tsimplis et al, 2013). In

55 addition to dominating the atmospheric component of sea level, a smaller influence of the

56 NAO has also been suggested on the thermosteric component (Tsimplis and Rixen, 2002;

57 Tsimplis et al., 2006; Tsimplis et al., 2013), and on the net evaporation (Tsimplis and

58 Josey, 2001; Mariotti et al., 2002; Fenoglio-Marc et al., 2013) of the Mediterranean Sea.

59 The Mediterranean Oscillation Index (MOI) has been successfully correlated with mean

60 sea level changes, especially during the winter season (Gomis et al 2006; Tsimplis and

61 Shaw, 2008); namely it has been shown to explain $46 \%$ of the winter sea level variance

62 for the period 1993-2001 (Suselj et al, 2008). It is worth noting, however, that the NAO

63 index and the MOI are not independent and are significantly correlated in winter. 
64 Raicich et al (2003) found that summer sea level atmospheric pressure in the 65 Mediterranean region is correlated with the Indian monsoon and the Sahel rainfall indices, 66 attributed to particular wind regimes over the area which in turn influenced coastal sea 67 level. Tsimplis and Shaw (2008) identified the East Atlantic pattern (EA) as an additional 68 atmospheric mode impacting sea level, but they only found significant correlations in the 69 Adriatic and once the atmospheric pressure effect was removed. Josey et al (2011) 70 suggested that at least in some parts of the Mediterranean Sea there is a distinct 71 contribution to heat fluxes linked with climatic indices different from NAO, such as the 72 East Atlantic (EA) and the East Atlantic/Western Russian (EA/WR) patterns. In particular 73 they identified correlations between the winter basin averaged heat fluxes and EA, 74 especially at Northwestern Mediterranean and Southern Adriatic, while the correlations 75 between each winter subbasin averaged and EA/WR were in opposite sense in each 76 region, with major values at Aegean Sea. The influence of these modes on heat fluxes 77 necessarily poses the question whether such modes affect at least the steric component of 78 sea level.

80 The present paper assesses and clarifies the influence of the four major atmospheric 81 modes over the North Atlantic, namely the NAO, the EA the EA/WR and SCAN, on 82 Mediterranean sea level as well as its component driven by wind and atmospheric 83 pressure changes and on the thermosteric component. The analysis is performed for 84 different periods dictated by the availability of tide gauge data and altimetry data. The 85 paper is organized as follows: Section 2 introduces the data sets to represent sea level and 86 its components and the climate indices. In Section 3 we present the methodology of the 87 analysis and in Section 4 we show the main results. Finally, a discussion and some 88 concluding remarks are presented in Sections 5 and 6.

\section{2. Data sets}

91 Sea level observations and estimates of the various contributions to sea level variability

92 have been obtained from the following data sources.

93

\section{$94 \quad 2.1$ Tide gauge data}


95 Monthly mean sea level values with benchmark history (Revised Local Reference, RLR)

96 were retrieved from tide gauge records archived at the Permanent Service for Mean Sea

97 Level (PSMSL; Woodworth and Player, 2003). We selected 12 tide gauges distributed

98 along the Mediterranean coasts, each of them spanning more than 35 years of the last

99 decades of the 20th century. The tide gauge stations and their periods of operation are

100 listed in Table 1. Finally, a set of atmospherically-corrected tide gauge records was

101 obtained through removing the atmospheric contribution as given by a sea level hindcast,

102 at the closest grid point to each tide gauge. The VANI2-ERA hindcast used is described 103 later.

105 2.2. Altimetry data

106 Gridded Sea Level Anomaly (SLA) fields were obtained from the merged AVISO 107 products available at http://www.aviso.oceanobs.com. The data consist of monthly 108 multimission (up to four satellites at a given time) gridded global sea surface heights 109 spanning the period $1993-2010$, with a spatial resolution of $1 / 4^{\circ} \times 1 / 4^{\circ}$. This version comes 110 with all the standard geophysical corrections applied including the so called Dynamic 111 Atmospheric Correction (DAC; Volkov et al 2007) that accounts for the effect of 112 atmospheric pressure and wind on sea level. This dataset will be referred to as DAC113 altimetry. The DAC correction, as supplied by AVISO, was added back to altimetry in 114 order to create a second data set accounting for the atmospheric pressure and wind effects 115 on sea level. This will be called altimetry. Note that because the dataset is a combination 116 of observations from different platforms there is significant uncertainty for the trends 117 derived especially for the last mission. In addition, the applied GIA corrections also 118 introduce significant errors in trends (Ablain et al., 2012). However we do not consider 119 these uncertainties as capable of affecting the correlation with the various atmospheric 120 modes because the variance linked to long term trends is much smaller than the 121 interannual variability analized here.

\section{2.3. Atmospherically-induced sea level}

124 The meteorological contribution to sea level caused by the combined action of 125 atmospheric pressure and wind was quantified from the VANI2-ERA data set (Jordà et 
126 al., 2012). VANI2-ERA data are 6-hourly sea surface heights obtained with a barotropic

127 version of the HAMSOM model forced with atmospheric pressure and winds from a

128 dynamical downscaling of the ERA40 reanalysis. The data span the period 1958-2008 and

129 cover the Mediterranean Sea and a sector of the NE Atlantic Ocean with a spatial

130 resolution of $1 / 6^{\circ} \times 1 / 4^{\circ}$. Two additional runs were also performed: one forced only by

131 wind and the other forced only by atmospheric pressure variations. Model hourly outputs

132 were converted into monthly fields at each grid point.

\section{2.4. Hydrographic data and thermosteric sea level}

135 Ocean temperature (T) fields from Ishii and Kimoto (2009; version 6.12) were used to

136 compute thermosteric sea level in the Mediterranean Sea (download website:

137 http://rda.ucar.edu/datasets/ds285.3/). The data set consists of monthly $\mathrm{T}$ fields over a

$1381^{\circ} \times 1^{\circ}$ global grid down to $1500 \mathrm{~m}$ and spanning the period $1950-2011$. Thermosteric sea

139 level was computed at each grid point over the Mediterranean Sea by vertically

140 integrating the specific volume anomaly at each grid cell down to $300 \mathrm{~m}$. The reference

141 level at $700 \mathrm{~m}$ was also sued for comparison, but the results did not differ. Therefore the

$142300 \mathrm{~m}$ reference level was preferred because there are a higher number of observations at

143 upper levels. Depths deeper than $700 \mathrm{~m}$ were not considered due to the scarcity of

144 observations. Salinity (S) values are also available in the same dataset. However, because

$145 \mathrm{~S}$ measurements are highly sparse and uncertain over the entire basin (Jordà and Gomis,

146 2013), thermosteric sea level was preferred instead of steric sea level. For the calculation

147 of the thermosteric height changes $S$ was considered constant to the 1950 value at each

148 depth.

$150 \quad 2.5$ Atmospheric variables

151 Mean sea level atmospheric pressure, $2 \mathrm{~m}$ air temperature, net heat fluxes and 10m wind

152 velocity, were obtained from NCEP/NCAR atmospheric reanalysis (Kistler et al., 2001).

153 We used monthly mean values obtained from the 6h output fields with a spatial resolution

154 of $2.5^{\circ} \times 2.5^{\circ}$ over the period $1950-2011$.

155 
157 The leading atmospheric climate modes used, namely NAO, EA, EA/WR and SCAN, as 158 computed for the period 1950-2011 were downloaded from the NOAA Climate Prediction 159 Centre (http://www.cpc.ncep.noaa.gov/data/teledoc/telecontents.shtml). These modes

160 were obtained through a rotated principal component analysis (Barnston and Livezey, 161 1987) of the monthly mean standardized 500-mb height anomalies in the Northern 162 Hemisphere. This ensured that they are orthogonal (independent) to each other at a 163 monthly scale. The source of the data is the same as that used by Josey et al (2011) 164 although the period covered in this study is longer. Our approach has considered the sea 165 level impacts of the four leading modes of atmospheric variability that have an influence 166 in the Mediterranean Sea region as identified by the NOAA Climate Prediction Centre 167 analysis. Other patterns can be defined but they are likely to reflect a combination of the 168 modes that we have already employed. Hence, our focus has been on these four modes. 169 Future research that considers Mediterranean sea level impacts of other patterns of 170 variability should be careful to identify the extent to which the other patterns are 171 dependent on those already considered here.

\section{3. Methodology}

175 Winter and summer averages, defined as the mean values over the period December to 176 March and June to August, respectively, were computed for each climate index. The 177 correlations among the seasonal averages of the climate indices used are listed in Table 2.

178 The NAO and SCAN are anticorrelated in winter. In the summer the EA, EA/WR and 179 SCAN are all correlated with each other.

181 Composite fields of $2 \mathrm{~m}$ air temperature, sea level pressure and wind anomalies were used 182 to develop spatial patterns of the relevant atmospheric field corresponding to the high and 183 low values of each index. The composite fields were built as follows: first, monthly fields 184 of the atmospheric variables coinciding with a climate index larger than 1.5 (or lower than $185-1.5)$ were selected. Each monthly field was then multiplied by the corresponding index 186 value and the resulting time series was weighted averaged. The pattern obtained in this 187 way can be considered associated with a unit positive value of the climate index. Using 
188 different thresholds for the climate indices did not alter significantly the results. The 189 resulting patterns for the positive phase of each index are shown in Figure 1.

191 Seasonal averages were calculated for the tide gauge records for the period December

192 to March (winter) and for the period June to August (summer). For the gridded data, 193 seasonally basin averaged time series, for the same periods, were obtained by

194 calculating averages over the whole Mediterranean basin as well as over the eastern

195 and western sub-basins (the Sicily Strait has been used as the separation line between

196 the eastern and western basins). Seasonal variances of the different data sets are

197 listed in Table 3. The values correspond to the basin averaged variance and its

198 standard deviation. The lowest and highest value for each data set is also shown for 199 comparison.

All time series were detrended and the seasonal cycle was removed before the regression analysis. The relationship between the various climate indices and sea level was explored 203 on the basis of the correlation and linear regression values between the seasonal (winter 204 and summer) anomalies of each variable and the corresponding seasonal time series of 205 each index. The trend removed corresponded to the common period of the time series and 206 the corresponding index. Significance was set at the 95\% level.

208 Multiple linear regression analysis was, in addition, performed with sea level or one of its 209 components as the dependent parameter and all four indices as independent parameters. 210 Note that the correlation between the seasonal values of the indices (Table 2) indicates 211 that there is the possibility that the same variance in sea level can be accounted for by 212 more than one index. Forward stepwise multiple linear regression analysis (Draper and 213 Smith, 1998) was used to select the statistically significant contributors. This procedure 214 selects the most correlated dependent variable and removes its influence through a 215 regression analysis. Then it checks for correlation between the rest of the dependent 216 parameters and the residual signal, until the correlation becomes non-significant. Where 217 more than one index can account for the same part of variability the regression model 218 favours the index that accounts for the highest percentage of total variability. 


\section{Results}

\subsection{Observed sea level from tide-gauges}

223 Correlations between seasonal climate indices and tide gauge records and atmospherically

224 corrected tide gauge records are shown in Figure 2. For some of the indices significant

225 differences can be found between eastern and western basins. The winter NAO is found to

226 be correlated with observed winter sea level at all sites. In the Adriatic it was also

227 correlated during summer at most stations. SCAN was positively correlated during winter

228 in the Adriatic stations as well as in Marseille and Genova. These similarities are in

229 agreement with the negative correlation of -0.47 found between winter NAO and SCAN

230 (Table 2). EA/WR was correlated with sea level during winter, in the Adriatic Sea and

231 Alexandria at the Eastern Mediterranean. The removal of the atmospheric forcing

232 component using VANI2-ERA hindcast reduced the correlation coefficients but did not

233 make the correlations statistically insignificant.

235 During the summer season the NAO is correlated with sea level in some Adriatic stations.

236 The EA is correlated in the Adriatic stations and Genova. The removal of the atmospheric

237 forcing component increased the correlation with the EA in the Adriatic.

238 The variance accounted for by the indices at each tide gauge record and the corresponding 239 atmospherically corrected tide gauge record are listed in Table 4. The results of the 240 regression analysis against the four modes are shown at Table 4. The results for the 241 multiple regression are shown in parenthesis. Note that although SCAN accounts for a 242 significant amount of the variance for the Adriatic stations and Genoa and Marseille in the 243 multiple regression model it is considered redundant by the selection process at most of 244 the tide gauges except in Venice and Rovinj. This is probably a consequence of the inter245 dependence of winter averaged NAO and SCAN.

247 The results of multiple regression indicate that the NAO is the leading mode for winter

248 sea level in the Mediterranean Sea, accounting for $13 \%$ to $47 \%$ of the variance of 249 observed sea level and for $7 \%$ to $26 \%$ of the variance of atmospherically corrected sea 
250 level. The EA/WR accounts for $6 \%$ to $22 \%$ in the Adriatic and the eastern sub-basin and

251 conserves similar values when the atmospheric correction is applied (8\% to 19\%). The

252 EA accounts for $6 \%-18 \%$ of the variance of corrected sea level. Overall, the climate

253 indices account for 39\%-56\% of the total inter-annual sea level variability in winter and

254 for $14 \%-41 \%$ when the atmospheric correction is applied. The multiple regression models

255 are shown in Fig.3.

256

257 During summer the influence of climates modes in sea level variability from tide gauges

258 is smaller. In the Adriatic the NAO accounted for $13 \%$ to $15 \%$ of the variance. The

259 correlation with the other indices seems random (Table 4 and Figure 3). However, the

260 summer EA accounts for $8 \%$ to $16 \%$ of the variance at Genova, Marseille and the Adriatic

261 tide gauges when the atmospheric contribution is removed.

\subsection{Observed sea level from altimetry}

264 Statistically significant winter correlations between the climate indices and altimetry are

265 mapped in Figure 4 (left column). The corresponding basin averaged correlation and the

266 variance accounted for is listed in Table 5. Summer maps are not shown because no

267 statistically significant correlation has been identified. The correlations with tide gauges,

268 but computed for the same period as the altimetry are also mapped for completeness

269 (Figure 4, left). The highest correlation for basin average was found between altimetry

270 and NAO (-0.91). The correlation with SCAN was slightly lower (0.75).

271 The multivariate regression model selects the NAO as the independent parameter while

272 the SCAN mode becomes redundant. For this reason the variance accounted for by SCAN

273 is zero in Table 5. The winter NAO accounts for $77 \%$ of the variance followed by EA/WR

274 (7\%) (Table 5 and Figure 5 top). These values are consistent with the variances of tide

275 gauges accounted for by the indices. However, the NAO accounts for more variance

276 during the altimetric period than for the tide-gauge period whereas the opposite is true for

277 EA/WR. Note that the EA/WR correlations are below the significance level for most of

278 the domain. Nevertheless it accounts for a small fraction of the variability. The multiple

279 regression model accounts for $83 \%$ of the basin averaged winter variance of sea level. 
280 Winter correlations between climate indices and DAC-altimetry are represented in Figure 2814 (right). The correlations with atmospherically corrected tide gauges are also mapped 282 over the DAC-altimetry maps. Basin and sub-basin averages of correlations and variances 283 accounted for by the indices according to the multiple regression model are listed in Table

284 5. No significant correlations were found in summer (not shown). The highest correlation 285 (in absolute values) was obtained with NAO (-0.9) SCAN having the second largest (0.6). 286 The correlation with EA was also significant over part of the western sub-basin, with an 287 average value of 0.5 .

The multiple regression model considered SCAN redundant. The contribution of each independent mode to winter atmospherically-corrected sea level variability averaged over the entire basin is represented in Figure 5 (bottom), being the NAO the only significant

292 mode, accounting for $78 \%$ of the variance. In the western sub-basin EA accounted for 293 around $12 \%$ of the variance.

295 It is worth to clarify that the difference in winter variances found between tide gauges $296(32 \pm 10 \mathrm{~cm} 2)$ and altimetry $(19 \pm 7 \mathrm{~cm} 2)$ listed in Table 3 is attributed to the different 297 periods considered and to the fact that the altimetry average covers the whole basin, while 298 the tide gauge value is point-wise. Indeed, when the winter variance of altimetry is 299 calculated by averaging only the closest grid points to tide gauges and limiting the tide 300 gauge average to the altimetry period this difference is significantly reduced $(11 \pm 4 \mathrm{~cm} 2$ 301 and $14 \pm 9 \mathrm{~cm} 2$, respectively).

\subsection{Atmospherically forced sea level}

304 Seasonal correlations between climate indices and atmospherically-induced sea level as 305 given by the barotropic hindcast forced by pressure and wind are mapped in Figure 6 for 306 winter (a-d) and summer (i-1). Basin averaged correlations and the corresponding 307 variances accounted for are listed in Table 6. With the exception of the EA, all other are 308 correlated with the winter atmospheric component of sea level. The highest correlation (309 0.7) is with NAO. For the winter season about $50 \%$ of the variance is accounted for by the 310 NAO index and $11 \%$ by the EA/WR. The correlation with SCAN was found redundant. 
311 Overall the variance accounted for by the climate modes was about $60 \%$. The statistical

312 model for the averaged basin sea level for the NAO alone and the NAO and EA/WR are

313 shown in Figure 7 (top).

315 It must be remarked however, that the atmospherically-induced sea level variability is

316 much smaller in summer than in winter; thus, the impacts of the climate modes are also

317 smaller in absolute terms.

319 During summer, SCAN explains $14 \%$ of the variance; the other modes do not show 320 statistically significant correlations (Table 6). Despite the low correlation obtained with 321 NAO (-0.19 over the basin), this mode accounts for $8 \%$ of the variability in the eastern 322 sub-basin, according to the regression model. The corresponding time series of the 323 summer atmospherically-induced sea level and the regression model are plotted in Figure 3247 (bottom).

326 Regression and correlation analysis was also performed for wind-only and pressure-only 327 forced sea level (Table 6). Seasonal correlations for wind-only forced sea level are 328 mapped at Figure 6 for winter (e-h) and summer (m-p). During winter, the NAO is the 329 leading mode for wind and pressure only forced sea level with very similar basin 330 averaged correlations $(-0.67$ and 0.68$)$ and corresponding variances accounted for 331 between $45 \%$ and $49 \%$.

332 For the multiple regression model of pressure-only forced sea level all four independent 333 modes contribute to winter basin-averaged sea level variability, reaching an overall value 334 of $60 \%$.

336 For the multiple regression model for wind-only forced sea level the EA/WR is the only 337 pattern which, together with NAO, contributed to the winter variance $(51 \%)$. Although 338 both EA and SCAN were correlated with wind sea level component at western subbasin 339 and overall the basin, respectively, they were considered redundant.

340 Results for the summer season are different. The pressure only forced sea level is 341 correlated with NAO at some areas of northern Adriatic and at 20-30 $\mathrm{E}$ area of Eastern 
342 sub-basin, while SCAN is correlated at western sub-basin. Interestingly, sea level forced

343 by wind only in summer is correlated only to the EA mode in almost all of the basin.

344 However the variance accounted for is only $9 \%$.

$346 \quad 4.4$ Thermosteric sea level

347 Thermosteric sea level has much smaller variance than the observed sea level and the

348 atmospherically-corrected sea level (Table 3). Thus any significant correlation found

349 should be interpreted in this context.

350 The results for winter correlations between climate indices and thermosteric sea level are

351 represented in Figure 8 (left) and Table 7. During winter, SCAN is the index that displays

352 higher correlation, concentrated over the central and eastern regions of the Mediterranean,

353 with an average value of 0.30 . SCAN explains about $9 \%$ of the winter basin averaged

354 thermosteric sea level variance. NAO is also correlated with the thermosteric sea level

355 over a fraction of the eastern sub-basin. The time series of the averaged thermosteric sea

356 level and the resulting regression models are plotted in Figure 9. No significant

357 correlations were found for the summer.

359 Changes in thermosteric sea level, at each part of the basin, result from atmospheric heat 360 fluxes and lateral heat advection. Significant correlation (0.59) was found between net 361 heat fluxes and the seasonal average of the time derivative of thermosteric sea level (0.59)

362 averaged over the basin for the period 1950-2008. Note that the seasonal average of the 363 time derivative of thermosteric sea level is the change in thermosteric sea level between 364 November and March divided by four, and between August and May divided by three.

365 The correlations with indices during winter and summer are mapped in Figure 8 (center 366 and right columns) and the averaged correlations and variances accounted for are listed in

367 Table 7. During winter, only EA is correlated over most of the western sub-basin and over 368 the Adriatic with an average value of 0.49 over all the basin. EA/WR shows correlations 369 in the most western and eastern parts of Mediterranean. However, the averaged values 370 have opposite sign depending on the sub-basin ( 0.30 and -0.22 , respectively). SCAN 371 show correlations only in the central parts of the eastern sub-basin (0.30). EA is the only

372 mode that explains part of the variance of the winter basin averaged rate of change of 
373 thermosteric (17\%). However, combined with EA/WR account for a $21 \%$ of the

374 variability of the basin, while combined with EA/WR and SCAN account for the $23 \%$ of

375 the eastern averaged. These results are consistent with Josey et al (2011) who showed that

376 EA is the mode driving air-sea net heat fluxes variability over the Mediterranean,

377 especially over western sub-basin, while the NAO and SCAN play much smaller role;

378 EA/WR also plays an important role, but generates a dipole with opposite signal on

379 western and eastern sub-basins. During summer only EA/WR is correlated with

380 thermosteric rate of change at the south part of the eastern sub-basin, however it is

381 correlated with the basin averaged (-0.35) accounting for $12 \%$ of the variance. SCAN

382 appears correlated at southern part of the western sub-basin (-0.29), where it explains

383 about $9 \%$ of the variance.

\section{5. Discussion}

387 The Mediterranean Sea level variance is larger in winter than in the summer. According to 388 altimetry it is about three times larger; according to coastal tide gauge records it is about 389 five times larger. The statistical modelling of this variance on multiple regression models 390 both for tide gauges and altimetric data show that the NAO can account for most of the 391 winter variability. The use of the atmospherically forced sea level hindcast shows that the 392 NAO influence is due both to the atmospheric pressure forcing and to wind forcing. The 393 sea level correlation with the NAO remains after the DAC correction is applied. This 394 means that the NAO influence on the Mediterranean is not restricted to the local 395 atmospheric pressure and wind effects.

396 Although SCAN and NAO are monthly independent, they are correlated in winter. All 397 modes show influence in the pressure driven part of the atmospheric forcing, hardly 398 surprising as they are determined on the basis of pressure changes. However only the 399 NAO and SCAN are correlated with the wind driven part of sea level in the winter. The 400 EA is the only mode influencing the wind driven sea level in the whole of the 401 Mediterranean Sea during the summer season.

402 The relationship between thermosteric sea level and the other large scale climate modes 403 considered in this study is not clearly demonstrated and the results found are spatially 
404 restricted to certain areas. Changes in the seasonally averaged rate of change of the 405 thermosteric sea level can be partly accounted for by the EA (21\% in winter and $12 \%$ in 406 summer) but with differences between the western and eastern sub-basins.

407 The physical mechanisms through which the atmospheric climate modes impact on 408 Mediterranean sea level and its contributions can be discussed further using composite 409 maps of anomalies of sea level components, wind speed and mean sea level pressure for 410 each pattern corresponding to index values higher than 1.5 or lower than -1.5 .

412 Figure 10 shows the composite maps of atmospherically forced winter sea level during the 413 positive and negative NAO phases and the corresponding map for EA/WR, the only two 414 indices we found accounting for the variance in the relevant multiple regression model. 415 Note that pressure and winds mapped here are not anomalies as in Figure 1. The spatial 416 pattern of the atmospheric component of sea level reflects that of the atmospheric 417 pressure: during a positive phase atmospheric pressure displays a meridional gradient with 418 lower values in the eastern sub-basin mimicked by the sea level response. On the 419 contrary, during a negative NAO phase, atmospheric pressure is lower and more 420 homogeneous within the basin and consequently sea level values are higher. The winds 421 associated with the NAO mode contribute in the same sense than atmospheric pressure to 422 the atmospherically-induced winter sea level. Fukumori et al. (2007) have shown that 423 winds around the Strait of Gibraltar can produce significant basin-wide oscillations in the 424 Mediterranean. Winds associated to the NAO negative phase are prone to induce a net 425 mass flux through the Strait of Gibraltar, so inducing a sea level increase in the basin 426 (Fukumori et al., 2007).

428 The second mode correlated with winter sea level and its atmospheric component, in the 429 multiple regression model, was the EA/WR. This mode was not significant for the 430 atmospherically-corrected sea level (Table 5), indicating thus that the influence on sea 431 level was exclusively through the atmospheric pressure and the local wind forcing. Wind 432 anomalies composites (Figure 1) suggested that positive phases of EA/WR favour 433 northerly strong winds, over the eastern basin. During a positive phase of EA/WR, the 434 atmospherically-induced sea level associated with this mode displays an E-W gradient in 
435 response to the atmospheric pressure pattern over the Mediterranean (Figure 10c). During 436 the negative phase of EA/WR (Figure 10d), the spatial pattern of atmospherically-induced 437 sea level is more uniform and dominated by westerly winds.

439 In Figure 11 composite maps for the anomalies in the rate of change of thermosteric sea 440 level are shown. As seen previously (Fig. 8), the NAO is only correlated with parts of the 441 Eastern Mediterranean. The winter EA is the mode most closely correlated with the rate 442 of change of thermosteric sea level. This is despite the fact that the EA does not correlate 443 with atmospherically-induced sea level in general but does correlate with the wind driven 444 part of the sea level. The underlying correlation between the wind field over the 445 Mediterranean and the EA is important for the heat fluxes. In its positive phase, EA is 446 characterized by an atmospheric pressure anomaly pattern with very weak gradients over 447 the Mediterranean Sea and the nearby Atlantic (Figure 1). The circulation associated with 448 the positive EA state involved westerly winds coming from the Atlantic, while the 449 negative phase northerly winds coming over the Gulf of Lions, in agreement with the 450 results presented by Josey et al (2011). As heat fluxes are always negative in winter, this 451 translates into smaller than average heat losses, especially over the western sub-basin 452 (Figure 11c). Likewise, the EA negative phase in winter is associated with northerly 453 winds and colder air $\mathrm{T}$, resulting in larger than average ocean heat losses and more 454 negative anomalies of the rate of change of thermosteric sea level (Figure 11d). The rates 455 of change of thermosteric sea level were found to be also related with EA/WR and SCAN 456 at some areas of the basin (Table 7 and Figure 11). The associated with EW/WR winter 457 wind fields show that during the positive phase of EA/WR northerly winds bring cold air 458 over some areas of the eastern sub-basin resulting in a higher than normal heat loss 459 (Figure 11e) while in the western part of the basin winds coming from the west 460 contributes to a lower than normal heat loss. The opposite effect occurs during the 461 negative phase of EA/WR, when a westerly flow of warmer air contributes to decreasing 462 the rates of change of the thermosteric component (Figure 11f). The positive phase of 463 SCAN is associated with a westerly flow of warm air that induces lower than normal 464 decreasing of thermosteric sea level, mostly over the central-eastern Mediterranean. In its 465 negative phase, there is a pattern of warmer north-westerly winds due to the absence of 
466 the low-pressure conditions over the western sub-basin and the result is a much lower

467 decreasing of thermosteric sea level than in the positive phase.

469 During the summer season, SCAN was the only relevant mode for summer 470 atmospherically-induced sea level, accounting for only $14 \%$ of the variance $(1.0 \pm 0.2 \mathrm{~cm} 2)$

471 on average over the basin. Figure 12a and $12 \mathrm{~b}$ show that the mechanism through which

472 the SCAN pattern impacts on the atmospheric contribution is its associated atmospheric

473 pressure pattern for both the positive and negative phases, as the atmospherically-induced 474 pattern follows that of the atmospheric pressure. EA/WR and, to a lesser extent, SCAN 475 patterns influenced the rates of change of thermosteric sea level during summer. For both 476 positive and negative phases, EA/WR induce northerly winds over the Mediterranean 477 (Figure 12c, d); however, air T over Europe is colder (warmer) than average during the 478 summer positive (negative) phase (not shown), which explains lower (higher) rates of 479 change of thermosteric sea level.

\section{Conclusions}

483 The four independent large scale modes dominating the atmospheric variability over the 484 North Atlantic and Europe (NAO, EA/WR, SCAN and EA), impact differently on sea 485 level and its components. Table 8 summarizes the results presented throughout the paper 486 for each sea level contribution.

The major conclusions of this work are summarized in the following:

- The NAO is the main mode in terms of impacts on winter Mediterranean sea level 491 variability $(-5.6 \mathrm{~cm}$ of altimetry sea level per unit NAO with a correlation of -0.91$)$ as a 492 result of two physical processes that contribute to amplify the atmospheric signal: i) the 493 direct forcing of atmospheric pressure and wind within the basin $(-2.9 \mathrm{~cm}$ per unit NAO 494 with a correlation of -0.71) which induces changes in the flux through Gibraltar, and ii) 495 the forcing of Gibraltar mass exchanges caused by winds near the Strait. In addition 496 Calafat et al. (2012) demonstrated that wind driven baroclinic circulation in the Atlantic 
497 also impact on Mediterranean sea level. Positive/negative winter NAO phases induce

498 lower/higher Mediterranean sea level as a result of these two mechanisms.

499 - The SCAN pattern is significantly correlated with winter Mediterranean sea level (0.89).

500 However, it has been found to be redundant with winter NAO, as the atmospheric patterns

501 associated with these two modes are very similar over the Mediterranean (confirmed by

502 the correlation between winter NAO and SCAN modes). Otherwise, SCAN is the only

503 mode that contributes to the winter thermosteric sea level with $0.4 \mathrm{~cm}$ per unit index.

504 - EA/WR is the second large scale mode in importance for Mediterranean sea level (-2.2

$505 \mathrm{~cm}$ of altimetry sea level per unit index and a correlation of -0.36), and acts mainly by

506 forcing the atmospheric sea level component, more particularly by atmospheric pressure

507 changes.

508 - The EA mode impacts on the rate of change in winter thermosteric sea level.

509 - In summer the variance of atmospherically induced sea level is much lower than in

510 winter $(1.0 \pm 0.2 \mathrm{~cm} 2)$. SCAN is correlated with atmospheric summer sea level $(0.38,0.6$

$511 \mathrm{~cm} / \mathrm{unit}$ ) and the effect is solely attributed to pressure. The EA is the only mode that

512 contributes to the wind-only induced sea level (-0.31) with $-0.2 \mathrm{~cm}$ per unit index but the

513 correlation is not significant for the atmospheric component as a whole or for the

514 observed sea level.

516 This work demonstrates that the study of the large-scale atmospheric variability can help

517 to understand sea level changes at a regional scale, at least for some of the sea level

518 components. Most notably, this is the first study that offers a complete overview of the

519 relationships between the major large-scale atmospheric patterns and Mediterranean sea

520 level and its components over the last decades. Our results provide both the relative and

521 overall contribution of atmospheric patterns to sea level variability in Mediterranean Sea,

522 an information that could be used for the study of past and future scenarios.

\section{Acknowlegdments}

525 This work has been carried out in the framework of the projects VANIMEDAT-2

526 (CTM2009-10163-C02-01, funded by the Spanish Marine Science and Technology

527 Program and the E-Plan of the Spanish Government) and ESCENARIOS (funded by the 
528 Agencia Estatal de METeorología). A. Martínez-Asensio acknowledges an FPI grant 529 associated with the VANIMEDAT-2 project, M. Marcos acknowledges a "Ramón y 530 Cajal" contract funded by the Spanish Government and G. Jordà acknowledges a JAE531 Doc contract funded by the Spanish Research Council (CSIC) and the European Science 532 Foundation. We are grateful to Météo-France for providing atmospheric reanalyses. 533 Finally we thank A. Sánchez-Román for his comments and data providers such as AVISO 534 for providing altimetry data, PSMLS for tide gauges data and NOAA for the climate 535 indices and the atmospheric reanalysis. We thank Piero Lionello and another anonymous 536 reviewer for their constructive comments.

\section{References}

539 Ablain, M., Philipps, S., Urvoy, M., Tran, N. and Picot,N., 2012. Detection of Long-Term 540 Instabilities on Altimeter Backscatter Coefficient Thanks to Wind Speed Data Comparisons from Altimeters and Models. Marine Geodesy 35:sup1, 258-275

542 Barnston, Anthony G., Robert E. Livezey, 1987. Classification, Seasonality and Persistence of Low-Frequency Atmospheric Circulation Patterns.Mon. Wea.

545 Calafat, F. M., G. Jordà, M. Marcos, and D. Gomis, 2012. Comparison of Mediterranean sea level variability as given by three baroclinic models, J. Geophys. Res., 117.

547 Cazenave A., Cabanes, C., Dominh, K. \& Mangiarotti, S., 2001. Recent sea level changes in the Mediterranean Sea revealed by TOPEX/POSEIDON satellite altimetry, Geophys. Res. Lett., 28(8), 1607-1610.

550 Church, J. A. and N.J. White, 2011. Sea-level rise from the late 19th to the early $21 \mathrm{st}$ Century. Surveys in Geophysics, 32, 585-602.

552 Criado-Aldeanueva, F., Del Río Vera, J., García-Lafuente, J., 2008. Steric and mass553 induced Mediterranean sea level trends from 14 years of altimetry data, Global and Planetary Change, 60, 3-4.

555 Draper, N. R. and Smith. H., 1998. Applied Regression Analysis. Hoboken, NJ: Wiley556 Interscience, 1998. pp. 307-312. 
557 Fenoglio-Marc, L., 2001. Analysis and representation of regional sea-level variability from altimetry and atmospheric-oceanic data. Geophys. J. Int., 145. 1-18.

559 Fenoglio-Marc, L., Mariotti, A., Sannino, G., Meyssignac, B., Carillo, A., Struglia, M.V., 560 Rixen, M. 2013. Decadal variability of net water flux at the Mediterranean Sea Gibraltar Strait, Global and Planetary Change, 100, 1-10.

562 Fukumori, Menemenlis, D. and Lee, T. 2007. A Near-Uniform Basin-Wide Sea Level 563 Fluctuation of the Mediterranean Sea. Journal of Physical Oceanography 37:2, $338-358$

Gomis, D., Tsimplis, M.N., Marcos, M., Fenoglio-Marc, L., Pérez, B., Raicich F., Vilibić I., Wöppelmann, G., Monserrat S., 2011. Sea Level Rise and its Forcing in the Mediterranean Sea. In: The Mediterranean climate from the present to the future, Lionello P. (ed.), Elsevier.

Gomis, D., S. Ruiz, M. García-Sotillo, E. Álvarez-Fanjul, and J. Terradas 2008. Low frequency Mediterranean sea level variability: The contribution of atmospheric pressure and wind, Global Planet. Change, 63, 215-229.

Ishii, M. and M. Kimoto, 2009: Reevaluation of Historical Ocean Heat Content Variations With An XBT depth bias Correction. J. Oceanogr. 65, 287299, doi:10.1007/s10872-009-0027-7.

Jordà, G., Gomis, D., Álvarez-Fanjul, E., 2012. The VANI2-ERA hindcast of sea-level residuals: Atmospheric forcing of sea-level variability in the Mediterranean Sea (1958-2008). Scientia Marina, 76, 133-146.

581 Josey, S. A., Kent, E. C. and Sinha, B. 2001. Can a state of the art atmospheric general 582 circulation model reproduce recent NAO related variability at the air-sea 583 interface?,Geophys. Res. Lett., 28, 4543-4546. 
584 Josey, S. A., S. Somot, and M. Tsimplis. 2011. Impacts of atmospheric modes of variability on Mediterranean Sea surface heat exchange, J. Geophys. Res., 116, C02032, doi:10.1029/2010JC006685

Kistler, R., E. Kalnay, W. Collins, S. Saha, G. White, J. Wollen, M. Chelliah, W. Ebisuzaki, M. Kanamitsu, V. Kousky, H. van den Dool, R. Jenne, and M. Fioriono, 2001: The NCEP/NCAR 50-year reanalysis: Monthly means CDROM and documentation. Bull. Am. Meteorol. Soc., 82, 247-267 Geophysical Journal International, 175: 70-82. doi: 10.1111/j.1365246X.2008.03892.X

Mariotti, A, Struglia, M. V., Zeng, N. and Lau, K-M., 2002: The Hydrological Cycle in 595 the Mediterranean Region and Implications for the Water Budget of the Mediterranean Sea. J. Climate, 15, 1674-1690.

Raicich, F., N. Pinardi, A. Navarra, 2003. Teleconnections between Indian monsoon and Sahel precipitation and the Mediterranean.Int. J. Clim., 23, 173-186

Suselj, Kay, Tsimplis, Michael N., Bergant, Klemen, 2008. Is the Mediterranean Sea surface height variability predictable? Phys.And Chem. Of the Earth, 33, 3-4, 225-238 DOI: 10.1016/j.pce.2006.12.001

Tsimplis MN, Baker TF (2000). Sea level drop in the Mediterranean Sea: an indicator of deep water salinity and temperature changes. Geophys. Res. Lett. 27(12):17311734.

Tsimplis, M.N. and S.A. Josey, 2001. Forcing of the Mediterranean Sea by Atmospheric Oscillations over the North Atlantic. Geophysical Research Letters,28(5), 803806.

609

Tsimplis, M.N., A.G.P. Shaw, 2008. The forcing of mean sea level variability around Europe. Global and Planetary Change 63, 196-202, doi:10.1016/j.gloplacha.2007.08.018. 
611 Tsimplis, M.N. and M. Rixen, 2002, Sea Level in the Mediterranean Sea: The contribution of temperature and salinity changes, Geophys. Res. Let.,29(23), 2136-2140.

614 Tsimplis, M., Shaw, A., Flather, R. and Woolf, D. 2006. The influence of the North Atlantic Oscillation on the sea level around the northern European coasts reconsidered: the thermosteric effects. Phil. Trans. R. Soc. A.364(1841), 845856.

618 Tsimplis, M. N., F. M. Calafat, M. Marcos, G. Jordà, D. Gomis, L. Fenoglio-Marc, M. V. Struglia, S. A. Josey, and D. P. Chambers (2013), The effect of the NAO on sea level and on mass changes in the Mediterranean Sea, J. Geophys. Res. Oceans, 118, doi:10.1002/jgrc.20078.

622 Volkov, D. L., G. Larnicol, and J. Dorandeu (2007), Improving the quality of satellite altimetry data over continental shelves, J. Geophys. Res., 112, C06020, doi:10.1029/2006JC003765.

625 Woodworth, P.L., Player, R., 2003. The permanent service for mean sea level: an update to the 21st century. J. Coast. Res. 19 (2), 287-295. 
642 Table 1. List of tide gauges, location, periods of operation and percentage of gaps

Period

\section{Malaga}

Alicante

Marseille

Genova

Venice

Trieste

Rovinj

Bakar

Split I

Split II

Dubrovnik

Alexandria
W. Med.

W. Med.

W. Med.

W. Med.

Adriatic

Adriatic

Adriatic

Adriatic

Adriatic

Adriatic

Adriatic

E. Med.

$3643 \mathrm{~N}$

$3820 \mathrm{~N}$

$4318 \mathrm{~N}$

$4424 \mathrm{~N}$

$4526 \mathrm{~N}$

$4539 \mathrm{~N}$

$4505 \mathrm{~N}$

$4518 \mathrm{~N}$

$4330 \mathrm{~N}$

$4330 \mathrm{~N}$

$4240 \mathrm{~N}$

$3113 \mathrm{~N}$

$0425 \mathrm{~W}$

$0029 \mathrm{~W}$

$0521 \mathrm{E}$

$0854 \mathrm{E}$

$1220 \mathrm{E}$

$1345 \mathrm{E}$

$1338 \mathrm{E}$

$1432 \mathrm{E}$

$1623 \mathrm{E}$

$1626 \mathrm{E}$

$1804 \mathrm{E}$

$2955 \mathrm{E}$

1950-2010

1960-1997

1950-2011

1950-1997

1950-2000

1950-2011

1955-2008

1950-2008

1952-2008

1954-2008

1956-2008

1950-1989
Gaps (\%)

15.00

2.70

0.00

6.38

2.00

1.64

1.89

1.72

1.79

1.85

1.92

2.56 
662 Table 2. Correlation coefficients between winter (upper right triangle of the matrix) and 663 summer (lower left triangle of the matrix, in italic) climate indices for the period 1950664 2012. Boldface values denote statistical significance at $95 \%$ level.

\begin{tabular}{lcccc} 
& $\boldsymbol{N A O}$ & $\boldsymbol{E A}$ & $\boldsymbol{E A} / \boldsymbol{W R}$ & $\boldsymbol{S C A N}$ \\
\hline $\boldsymbol{N A \boldsymbol { O }}$ & 1.00 & 0.11 & 0.05 & $\mathbf{- 0 . 4 2}$ \\
$\boldsymbol{E A}$ & -0.20 & 1.00 & 0.02 & 0.00 \\
$\boldsymbol{E A} / \boldsymbol{W R}$ & 0.20 & $\mathbf{- 0 . 3 7}$ & 1.00 & -0.16 \\
$\boldsymbol{S C A N}$ & 0.17 & $\mathbf{- 0 . 2 7}$ & $\mathbf{0 . 2 5}$ & 1.00
\end{tabular}

670 Table 3. Mean and standard deviation of winter and summer variance of each data set.

671 For tide gauges and atmospherically-corrected tide gauges the variance of each tide gauge

672 was calculated and then the average value and the STD are shown. For sea level

673 altimetry, DAC-Altimetry, atmospheric component, pressure-only and wind-only

674 components and thermosteric sea level the variance at each grid point has been calculated 675 and then the average and STD are shown. The lowest and highest variances of each data 676 set are also shown (in brackets). (*) The units for the thermosteric rate of change are $677 \mathrm{~cm} / \mathrm{month}$.

\begin{tabular}{lcc}
\hline Tide gauges & $32 \pm 10(17-44)$ & $7 \pm 2(2-10)$ \\
Atm-Corr. Tide gauges & $11 \pm 2(5-15)$ & $5 \pm 2(1-10)$ \\
Altimetry & $19 \pm 7(6-73)$ & $6 \pm 6(1-64)$ \\
DAC-Altimetry & $11 \pm 7(3-81)$ & $6 \pm 6(1-63)$ \\
Atmospheric component & $6.1 \pm 2.1(2.2-13.7)$ & $0.6 \pm 0.1(0.2-1.2)$ \\
Pressure-only component & $3.3 \pm 1.5(0.5-6.3)$ & $0.4 \pm 0.1(0.1-0.6)$ \\
Wind-only component & $0.7 \pm 0.2(0.4-2.8)$ & $0.1 \pm 0.0(0.1-0.4)$ \\
Thermosteric component & $0.9 \pm 0.5(0.0-2.5)$ & $1.5 \pm 0.8(0.0-4.6)$ \\
Thermost. rate of change $*$ & $0.2 \pm 0.1(0.0-0.5)$ & $0.4 \pm 0.1(0.0-0.5)$
\end{tabular}


684 Table 4. The percentage of the variance accounted for by each climatic index at each tide 685 gauge for winter (above) and summer (below) for a regression model in which only one 686 index is the independent parameter. In brackets the corresponding variance for the 687 multiple regression model.

Variance accounted for

\begin{tabular}{lcccc|cccc} 
& \multicolumn{3}{c}{ Winter sea level } & \multicolumn{3}{c}{$\begin{array}{c}\text { inter atmospherically- } \\
\text { corrected sea level }\end{array}$} \\
\cline { 2 - 9 } Station & NAO & $\boldsymbol{E A}$ & $\boldsymbol{E A} / \boldsymbol{W R}$ & SCAN & NAO & EA & EA/WR & SCAN \\
\hline Málaga & $40(40)$ & $3(0)$ & $0(0)$ & $1(0)$ & $7(0)$ & $4(0)$ & $4(0)$ & $1(0)$ \\
Alicante & $47(47)$ & $5(0)$ & $0.4(0)$ & $7(0)$ & $20(15)$ & $14(9)$ & $0(0)$ & $2(0)$ \\
Marseille & $32(29)$ & $10(7)$ & $1(0)$ & $12(0)$ & $10(7)$ & $22(18)$ & $0(0)$ & $4(0)$ \\
Genova & $44(43)$ & $10(0)$ & $8(6)$ & $24(0)$ & $19(14)$ & $19(14)$ & $0(0)$ & $8(0)$ \\
Venice & $24(13)$ & $1(0)$ & $25(18)$ & $25(9)$ & $14(0)$ & $5(0)$ & $26(19)$ & $21(14)$ \\
Trieste & $33(33)$ & $5(0)$ & $20(20)$ & $20(0)$ & $14(11)$ & $9(6)$ & $15(14)$ & $7(0)$ \\
Rovinj & $35(26)$ & $5(0)$ & $16(14)$ & $22(5)$ & $18(16)$ & $11(7)$ & $11(11)$ & $11(0)$ \\
Bakar & $32(32)$ & $4(0)$ & $22(22)$ & $19(0)$ & $18(18)$ & $6(0)$ & $17(17)$ & $7(0)$ \\
Split 1 & $39(39)$ & $1(0)$ & $17(17)$ & $18(0)$ & $24(24)$ & $3(0)$ & $9(9)$ & $7(0)$ \\
Split 2 & $39(39)$ & $2(0)$ & $15(15)$ & $18(0)$ & $21(21)$ & $5(0)$ & $8(8)$ & $7(0)$ \\
Dubrovnik & $40(40)$ & $0(0)$ & $17(17)$ & $18(0)$ & $26(26)$ & $2(0)$ & $14(14)$ & $12(0)$ \\
Alexandria & $17(16)$ & $1(0)$ & $16(15)$ & $0(0)$ & $7(0)$ & $2(0)$ & $14(14)$ & $2(0)$
\end{tabular}

\begin{tabular}{lcccc|cccc} 
& \multicolumn{3}{c}{ Summer sea level } & \multicolumn{3}{c}{$\begin{array}{c}\text { Summer atmospherically- } \\
\text { corrected sea level }\end{array}$} \\
\cline { 2 - 7 } & NAO & EA & EA/WR & SCAN & NAO & EA & EA/WR & SCAN \\
\hline Málaga & $3(0)$ & $2(0)$ & $7(0)$ & $1(0)$ & $3(0)$ & $4(0)$ & $8(0)$ & $0(0)$ \\
Alicante & $0(0)$ & $1(0)$ & $0(0)$ & $18(18)$ & $0(0)$ & $4(0)$ & $0(0)$ & $7(0)$ \\
Marseille & $2(0)$ & $6(0)$ & $0(0)$ & $2(0)$ & $1(0)$ & $11(11)$ & $0(0)$ & $0(0)$ \\
Genova & $3(0)$ & $16(16)$ & $2(0)$ & $0(0)$ & $0(0)$ & $14(14)$ & $2(0)$ & $2(0)$ \\
Venice & $5(0)$ & $6(0)$ & $6(0)$ & $1(0)$ & $2(0)$ & $6(0)$ & $5(0)$ & $0(0)$ \\
Trieste & $15(15)$ & $8(0)$ & $5(0)$ & $1(0)$ & $10(0)$ & $13(13)$ & $7(0)$ & $0(0)$ \\
Rovinj & $13(10)$ & $11(8)$ & $5(0)$ & $0(0)$ & $7(0)$ & $16(16)$ & $7(0)$ & $1(0)$ \\
Bakar & $13(13)$ & $7(0)$ & $4(0)$ & $0(0)$ & $6(0)$ & $9(9)$ & $5(0)$ & $1(0)$ \\
Split 1 & $14(14)$ & $10(0)$ & $5(0)$ & $0(0)$ & $11(1)$ & $14(11)$ & $6(0)$ & $2(0)$ \\
Split 2 & $15(15)$ & $10(0)$ & $2(0)$ & $0(0)$ & $11(7)$ & $15(11)$ & $2(0)$ & $2(0)$ \\
Dubrovnik & $5(0)$ & $5(0)$ & $2(0)$ & $0(0)$ & $4(0)$ & $8(8)$ & $3(0)$ & $2(0)$ \\
Alexandria & $2(0)$ & $0(0)$ & $1(0)$ & $1(0)$ & $1(0)$ & $0(0)$ & $1(0)$ & $2(0)$
\end{tabular}


693 Table 5. Correlation coefficients and the variance accounted for, by the regression model

694 in which each climate index has been regressed against the corresponding sea level

695 parameter. Results for winter are shown. The variance accounted for by the multiple

696 regression model is shown in brackets. Boldface values denote statistically significance at 697 95\% level. Western and Eastern Mediterranean values are also shown.

698

\begin{tabular}{|c|c|c|c|c|c|c|c|c|c|}
\hline & \multicolumn{2}{|c|}{$N A O$} & \multicolumn{2}{|c|}{$\boldsymbol{E A}$} & \multicolumn{2}{|c|}{$E A / W R$} & \multicolumn{2}{|c|}{$S C A N$} \\
\hline & & Corr & $E V(\%)$ & Corr & $E V(\%)$ & Corr & $E V(\%)$ & Corr & $E V(\%)$ \\
\hline \multirow{3}{*}{ Altimetry } & Med & -0.91 & $83(77)$ & 0.10 & $1(0)$ & -0.36 & $13(7)$ & 0.75 & $56(0)$ \\
\hline & WMed & -0.90 & $81(76)$ & 0.19 & $4(0)$ & -0.35 & $12(7)$ & 0.78 & $61(0)$ \\
\hline & EMed & -0.89 & $79(73)$ & 0.08 & $1(0)$ & -0.36 & $13(7)$ & 0.73 & $53(0)$ \\
\hline \multirow{3}{*}{ DAC Altimetry } & Med & -0.89 & 79 (79) & 0.26 & $7(0)$ & -0.20 & $4(0)$ & 0.57 & $32(0)$ \\
\hline & WMed & -0.80 & $64(52)$ & 0.49 & $24(12)$ & -0.05 & $0(0)$ & 0.48 & $23(0)$ \\
\hline & EMed & -0.89 & 79 (79) & 0.21 & $4(0)$ & -0.23 & $5(0)$ & 0.60 & $36(0)$ \\
\hline
\end{tabular}

699

700

701

702

703

704

705

706

707

708

709

710

711

712

713

714

715

716 
718 Table 6. Correlation coefficients and the variance accounted for, by the regression model

719 in which each climate index has been regressed against the atmospherically-induced sea

720 level, pressure only-induced sea level and wind only-induced sea level. Results for winter

721 (above) and summer (below) are shown. The variance accounted for by the multiple

722 regression model is shown in brackets. Boldface values denote statistically significance at

$72395 \%$ level. Western and Eastern Mediterranean values are also shown.

\begin{tabular}{|c|c|c|c|c|c|c|c|c|c|}
\hline & \multicolumn{2}{|c|}{$N A O$} & \multicolumn{2}{|c|}{$\boldsymbol{E A}$} & \multicolumn{2}{|c|}{$E A / W R$} & \multicolumn{2}{|c|}{$S C A N$} \\
\hline & & Corr & $E V(\%)$ & Corr & $E V(\%)$ & Corr & $E V(\%)$ & Corr & $E V(\%)$ \\
\hline \multirow{3}{*}{$\begin{array}{c}\text { Winter } \\
\text { Atmospheric }\end{array}$} & Med & -0.71 & $50(50)$ & -0.01 & $0(0)$ & -0.32 & $10(11)$ & 0.47 & $22(0)$ \\
\hline & Wmed & -0.73 & $53(42)$ & 0.03 & $0(0)$ & -0.26 & $7(5)$ & 0.49 & $24(4)$ \\
\hline & Emed & -0.67 & $45(45)$ & -0.04 & $0(0)$ & -0.35 & $12(13)$ & 0.43 & $18(0)$ \\
\hline \multirow{3}{*}{$\begin{array}{c}\text { Winter } \\
\text { Pressure-only }\end{array}$} & Med & -0.68 & 46 (49) & -0.12 & $1(4)$ & -0.33 & $11(12)$ & 0.47 & $22(0)$ \\
\hline & Wmed & -0.70 & 49 (38) & -0.06 & $0(0)$ & -0.30 & $9(7)$ & 0.51 & $26(5)$ \\
\hline & Emed & -0.63 & $39(44)$ & -0.15 & $2(6)$ & -0.35 & $12(13)$ & 0.4 & $16(0)$ \\
\hline \multirow{3}{*}{$\begin{array}{c}\text { Winter } \\
\text { Wind-only }\end{array}$} & Med & -0.67 & $45(45)$ & 0.21 & $4(0)$ & -0.25 & $6(7)$ & 0.42 & $18(0)$ \\
\hline & Wmed & -0.67 & $45(45)$ & 0.28 & $8(0)$ & -0.10 & $1(0)$ & 0.34 & $12(0)$ \\
\hline & Emed & -0.65 & $42(42)$ & 0.17 & $3(0)$ & -0.30 & $9(9)$ & 0.44 & $19(0)$ \\
\hline
\end{tabular}

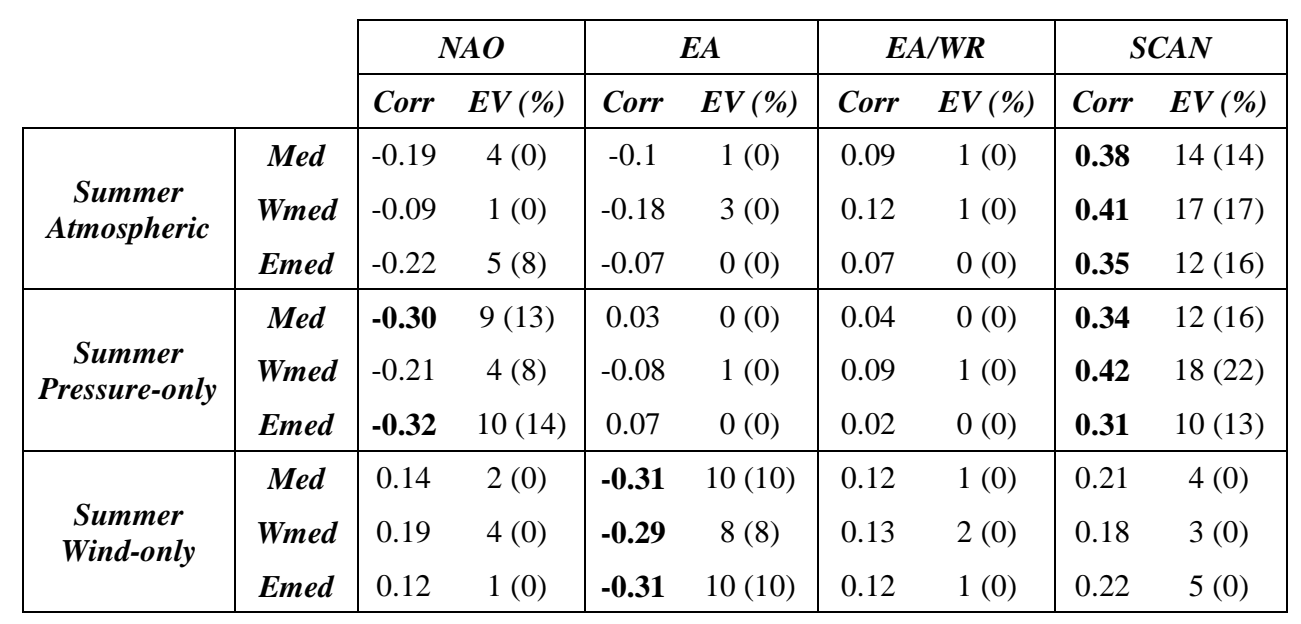


730 Table 7. Correlation coefficients and the variance account for, by the regression

731 model in which each climate index has been regressed against the thermosteric sea

732 level and the monthly rate of change of thermosteric sea level. Results for winter are

733 shown. Results for summer are shown only for the rate of change of thermosteric.

734 The variance accounted for by the multiple regression model is shown in brackets.

735 Boldface values denote statistically significance at 95\% level. Western and Eastern

736 Mediterranean values are also shown.

737

738

739

\begin{tabular}{|c|c|c|c|c|c|c|c|c|c|}
\hline & \multicolumn{2}{|c|}{$N A O$} & \multicolumn{2}{|c|}{$E A$} & \multicolumn{2}{|c|}{$E A / W R$} & \multicolumn{2}{|c|}{ SCAN } \\
\hline & & Corr & $E V(\%)$ & Corr & $E V(\%)$ & Corr & $E V(\%)$ & Corr & $E V(\%)$ \\
\hline \multirow{3}{*}{$\begin{array}{c}\text { Winter } \\
\text { Thermosteric }\end{array}$} & Med & -0.23 & $5(0)$ & -0.20 & $4(0)$ & -0.04 & $0(0)$ & 0.30 & $9(9)$ \\
\hline & Wmed & -0.02 & $0(0)$ & -0.10 & $1(0)$ & 0.05 & $0(0)$ & 0.15 & $2(0)$ \\
\hline & Emed & -0.28 & $8(0)$ & -0.21 & $4(6)$ & -0.06 & $0(0)$ & 0.32 & $10(12)$ \\
\hline \multirow{3}{*}{$\begin{array}{l}\text { Winter Rate } \\
\text { of change }\end{array}$} & Med & -0.18 & $3(0)$ & 0.49 & $24(17)$ & -0.22 & $5(4)$ & 0.21 & $4(0)$ \\
\hline & Wmed & 0.09 & $1(0)$ & 0.44 & $19(16)$ & 0.10 & $1(0)$ & -0.14 & $2(0)$ \\
\hline & Emed & -0.25 & $6(0)$ & 0.40 & $16(11)$ & -0.30 & $9(6)$ & 0.30 & $9(4)$ \\
\hline \multirow{3}{*}{$\begin{array}{c}\text { Summer Rate } \\
\text { of Change }\end{array}$} & Med & 0.06 & $0(0)$ & 0.13 & $2(0)$ & -0.35 & $12(12)$ & -0.19 & $3(0)$ \\
\hline & Wmed & -0.05 & & -0.06 & $0(0)$ & -0.09 & & -0.29 & $9(9)$ \\
\hline & Emed & 0.09 & $1(0)$ & 0.18 & $3(0)$ & -0.37 & $14(14)$ & -0.09 & $1(0)$ \\
\hline
\end{tabular}

740 
753 Table 8. Variance accounted for by the regression model in which each climate index has

754 been regressed against the sea level and its components for the altimetry period (1993755 2008). The variances of the altimetric sea level accounted for by the atmospheric and 756 thermosteric components are also shown. Results for winter and summer are shown. The 757 variance accounted for by the multiple regression model is shown in parentheses. The 758 lowest and highest variances accounted for by each tide gauge are also shown for the 759 altimetry period (in brackets).

\begin{tabular}{|c|c|c|c|c|c|c|c|c|c|c|c|c|}
\hline & \multicolumn{2}{|c|}{ Altimetry } & \multicolumn{2}{|c|}{$\begin{array}{c}\text { DAC- } \\
\text { Altimetry }\end{array}$} & \multicolumn{2}{|c|}{$\begin{array}{l}\text { Atmospheric } \\
\text { component }\end{array}$} & \multicolumn{2}{|c|}{$\begin{array}{l}\text { Thermosteric } \\
\text { component }\end{array}$} & \multicolumn{2}{|c|}{$\begin{array}{l}\text { Tide } \\
\text { gauges }\end{array}$} & \multicolumn{2}{|c|}{$\begin{array}{c}\text { Atm-corrected } \\
\text { tide gauges }\end{array}$} \\
\hline & Win & Sum & Win & Sum & Win & Sum & Win & Sum & Win & Sum & Win & Sum \\
\hline$N A O(\%)$ & $86(86)$ & $0(0)$ & 72(72) & $0(0)$ & $70(0)$ & $1(0)$ & $2(0)$ & $6(0)$ & $\begin{array}{l}{[31-64]} \\
([045])\end{array}$ & [0-15] & $\begin{array}{c}{[7-56]} \\
([0-54])\end{array}$ & {$[0-2](0)$} \\
\hline$E A(\%)$ & $0(0)$ & $5(0)$ & $1(0)$ & $3(0)$ & $3(0)$ & $0(0)$ & $0(0)$ & $6(0)$ & {$[0-4](0)$} & [0-16] & {$[2-14](0)$} & {$[0-7](0)$} \\
\hline$E A / W R(\%)$ & 1(0) & $0(0)$ & $0(0)$ & $1(0)$ & $2(0)$ & $2(0)$ & $19(0)$ & $2(0)$ & {$[0-7](0)$} & 0 & {$[0-5](0)$} & {$[0-3](0)$} \\
\hline$S C A N(\%)$ & $60(0)$ & $0(0)$ & $25(0)$ & $1(0)$ & $80(80)$ & $10(0)$ & $2(0)$ & $0(0)$ & $\begin{array}{l}{[10-65]} \\
([063])\end{array}$ & [0-18] & {$[1-37](0)$} & {$[0-5](0)$} \\
\hline $\begin{array}{c}\text { Atmospheric } \\
\text { Component (\%) }\end{array}$ & 74 & 42 & - & - & - & - & - & - & - & - & - & - \\
\hline $\begin{array}{c}\text { Thermosteric } \\
\text { Component (\%) }\end{array}$ & 0 & 0 & 0 & 1 & - & - & - & - & - & - & - & - \\
\hline
\end{tabular}




\section{Figures}

781

782

783

784

785

786 787

788

789

790

791

792

793

794

795

796

797

798

799

Figure 1. Winter (Dec-Mar) NCEP $2 \mathrm{~m}$ air temperature anomalies (coloured field, ${ }^{\circ} \mathrm{C}$ ), $10 \mathrm{~m}$ wind speed anomalies (vectors) and sea level pressure anomalies (contours) for a unit value of the positive index of: (a) NAO, (b) EA, (c) EA/WR and (d) SCAN. Note that the horizontal vector (red arrow) is for scale and indicates a wind speed of $5 \mathrm{~m} / \mathrm{s}$.
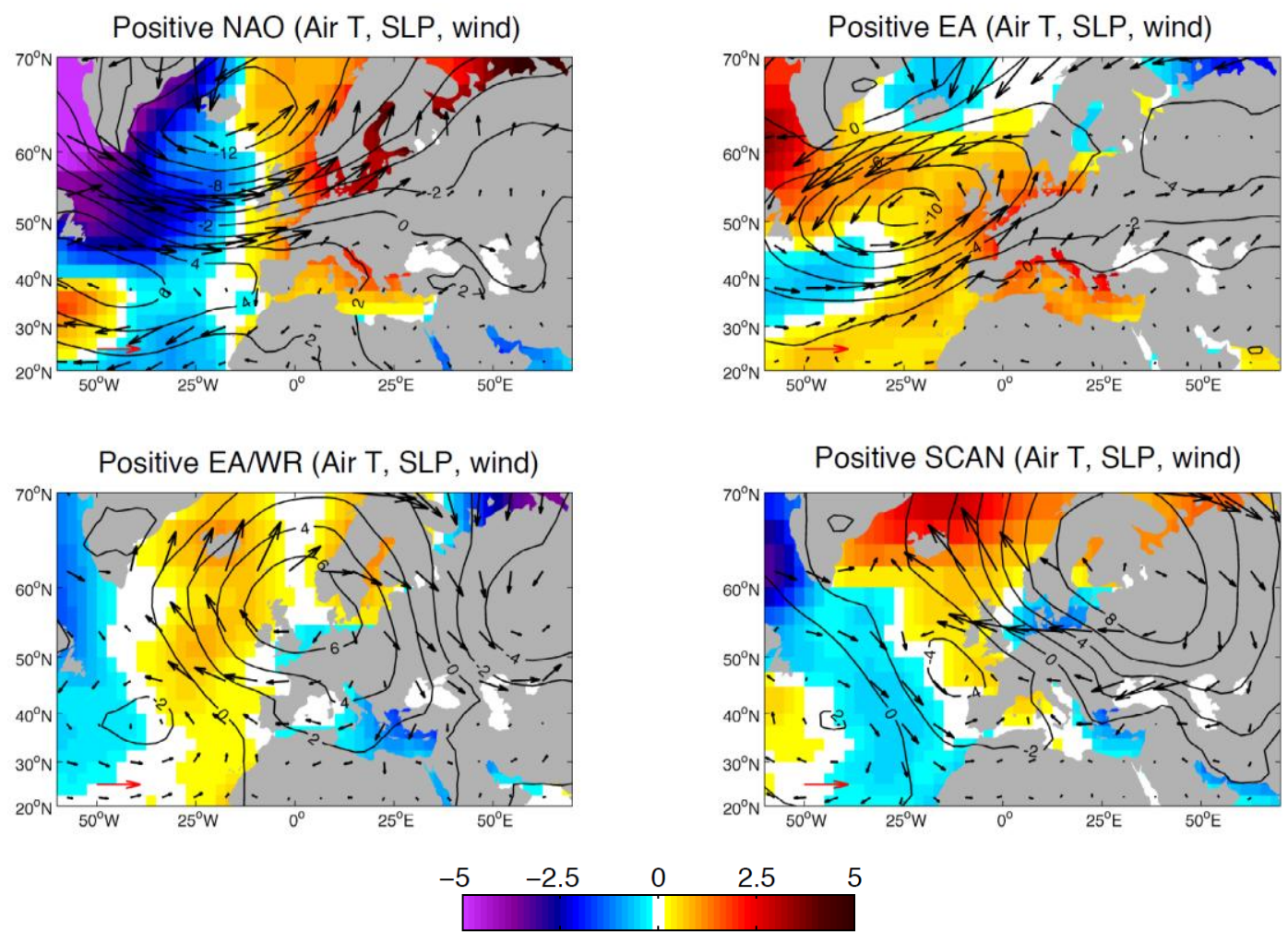

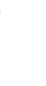


801 Figure 2. Dec-Mar (triangles and stars) and Jun-Aug (circles and squares) correlation

802 coefficients between NAO (a), EA (b), EA/WR (c), SCAN (d) and tide gauges (black) and

803 atmospherically corrected tide gauges (grey) for the common period 1958-2008. Filled

804 symbols denote statistically significance at 95\% level. Site names are listed in Table 1.

805
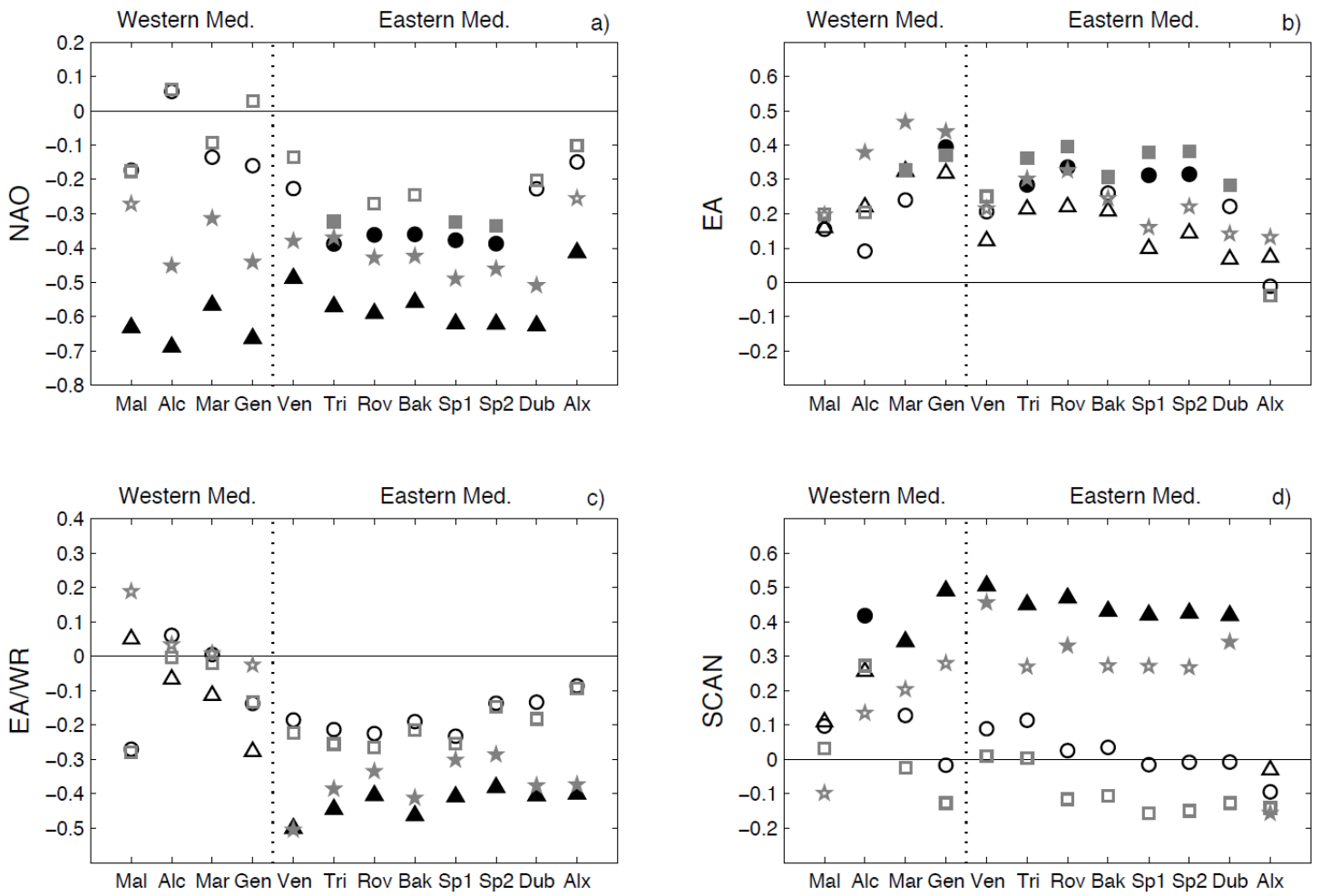
818 Figure 3. Winter (left) and summer (right) sea level at tide gauges (in grey) and time 819 series reconstructed using the multiple regression model (black lines) with the 820 corresponding indices (Figure 2 and Table 4).

821
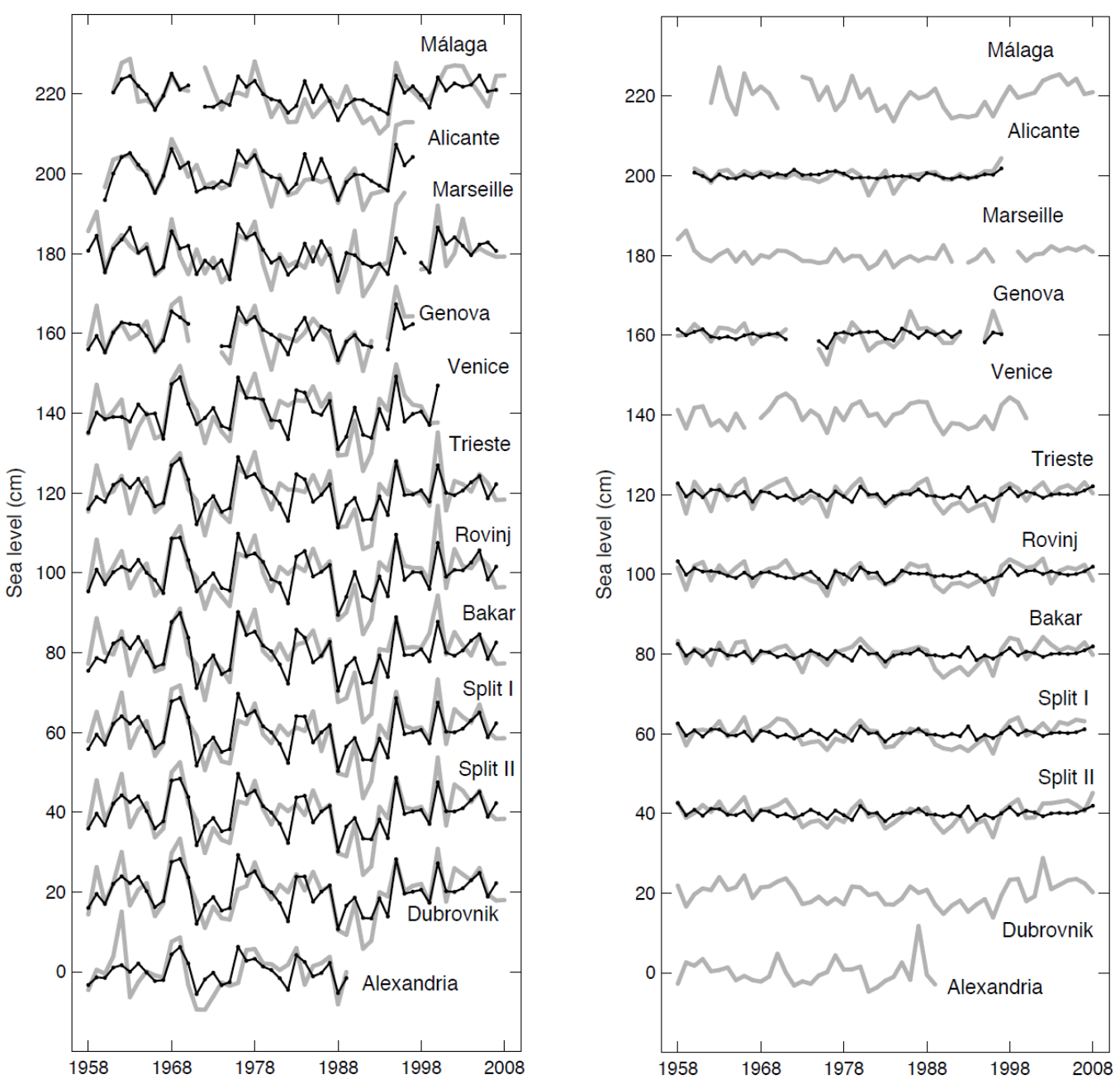

823 
833 Figure 4. Maps of the correlation coefficient between winter climate indices and

834 winter altimetry (left) and DAC-altimetry (right) for the period 1993-2010. Dotted

835 areas denote significant correlation at 95\% level. Correlations with tide gauges are

836 also shown for the same period (coloured circles). Only those tide gauges longer than

83710 years of data during 1993-2010 are shown.

838
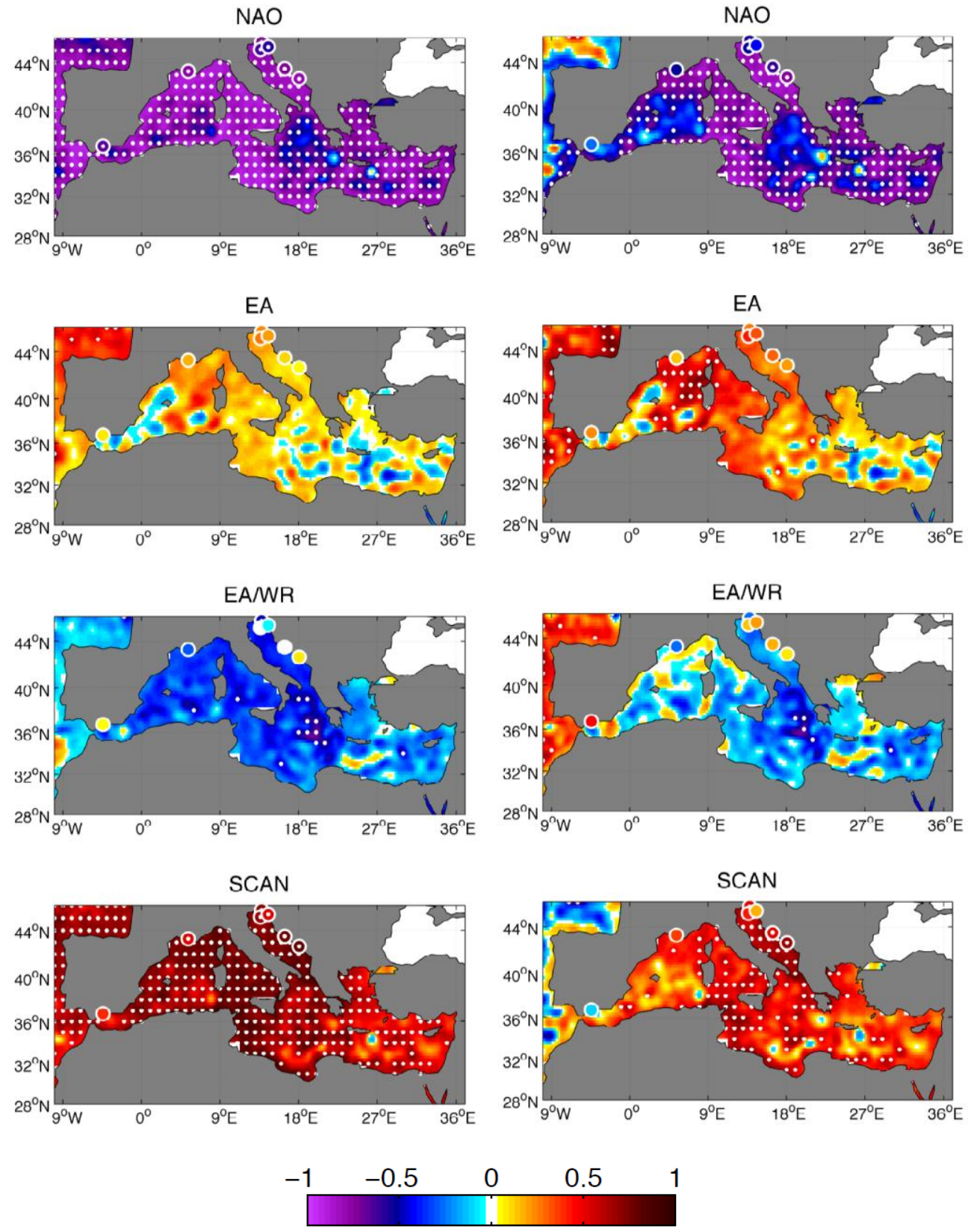
843 Figure 5. Overall contribution of independent modes to winter basin average

844 altimetry (top) and winter basin average DAC-altimetry (bottom).

845
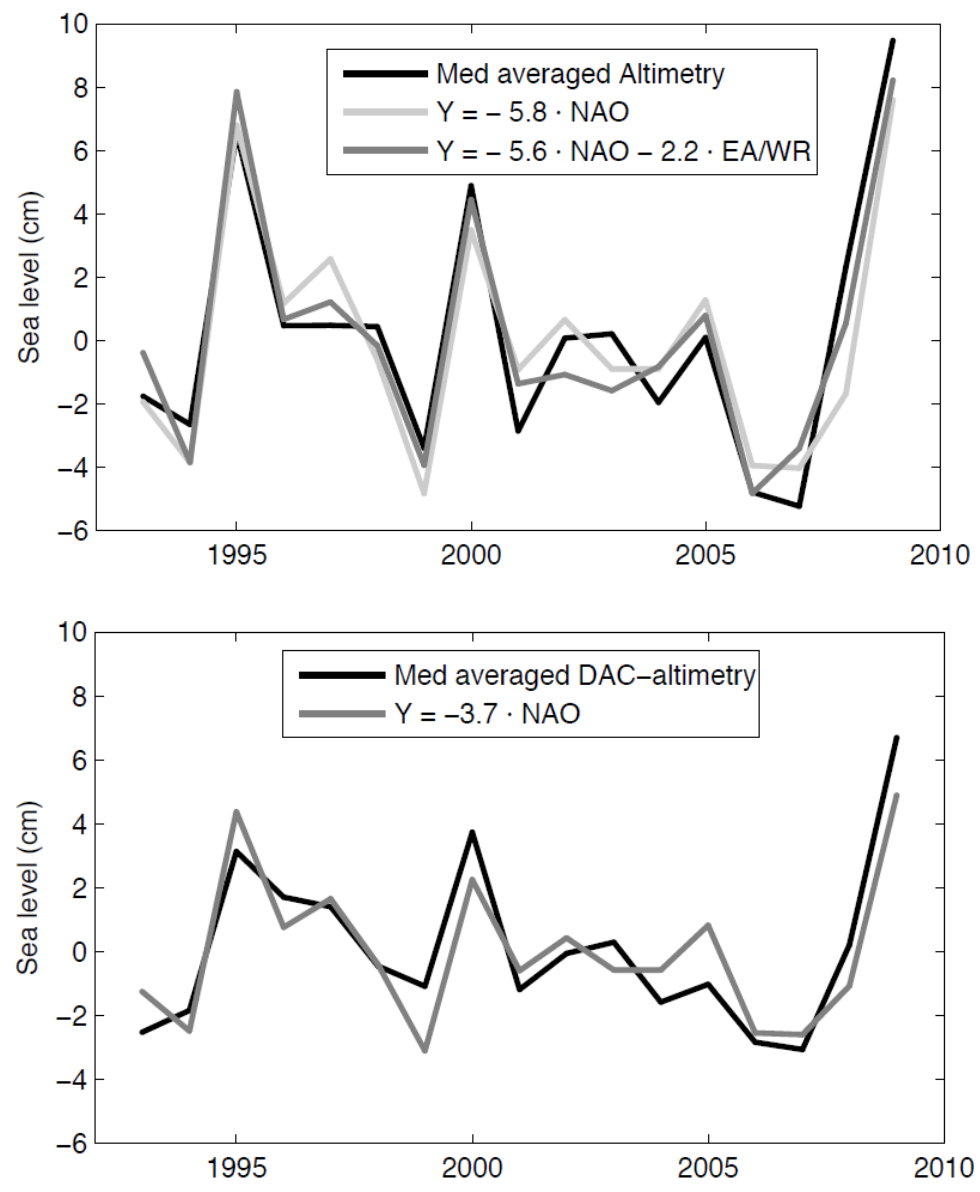
859 Figure 6. Dec-Mar and Jun-Aug maps of correlation coefficients between climate

860 modes and atmospherically-induced sea level and wind-only induced sea level for the

861 period 1958-2008. Dotted areas denote significant correlation at 95\% level.

862

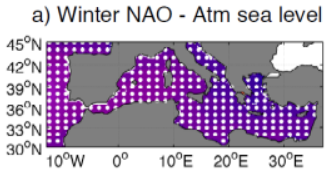

b) Winter EA - Atm sea level

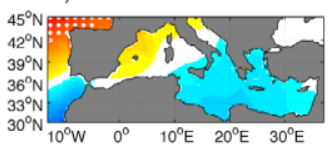

c) Winter EAWR - Atm sea level

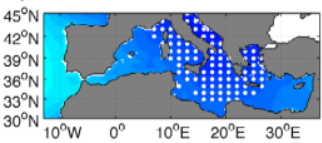

d) Winter SCAN - Atm sea level

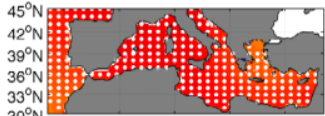

863

864

865

866

867

868

869

870

871

872

873

874

875

876

877

878
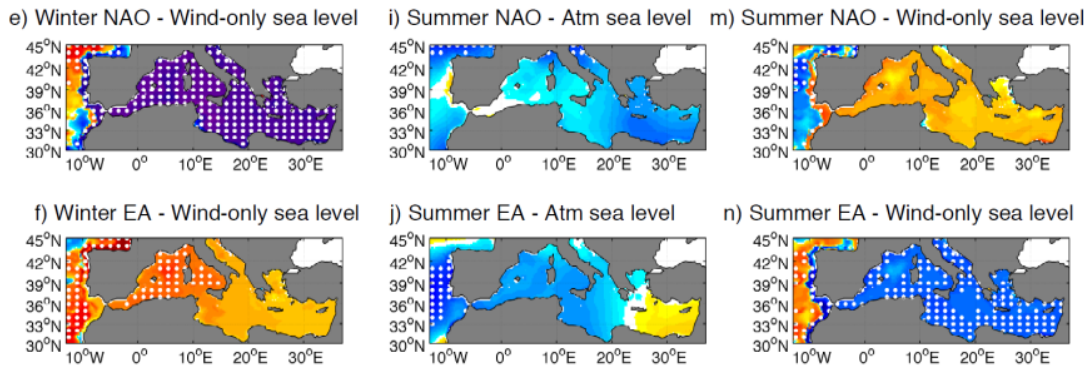

n) Summer EA - Wind-only sea level
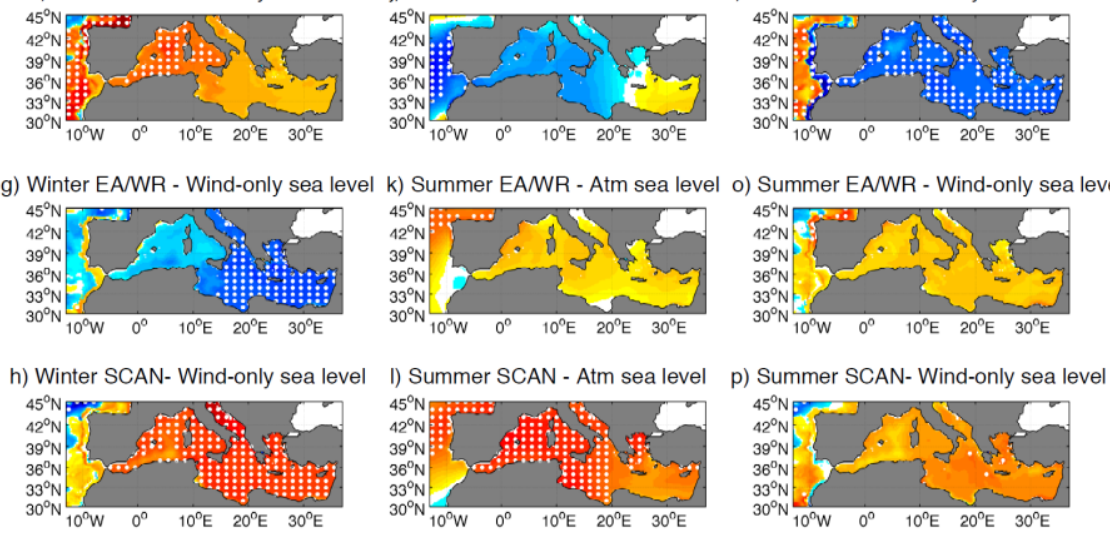

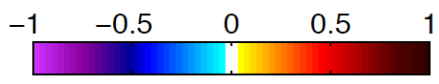


881 Figure 7. Overall contribution of independent modes to winter (top) and summer 882 (bottom) basin average atmospherically induced sea level variability.

883

884
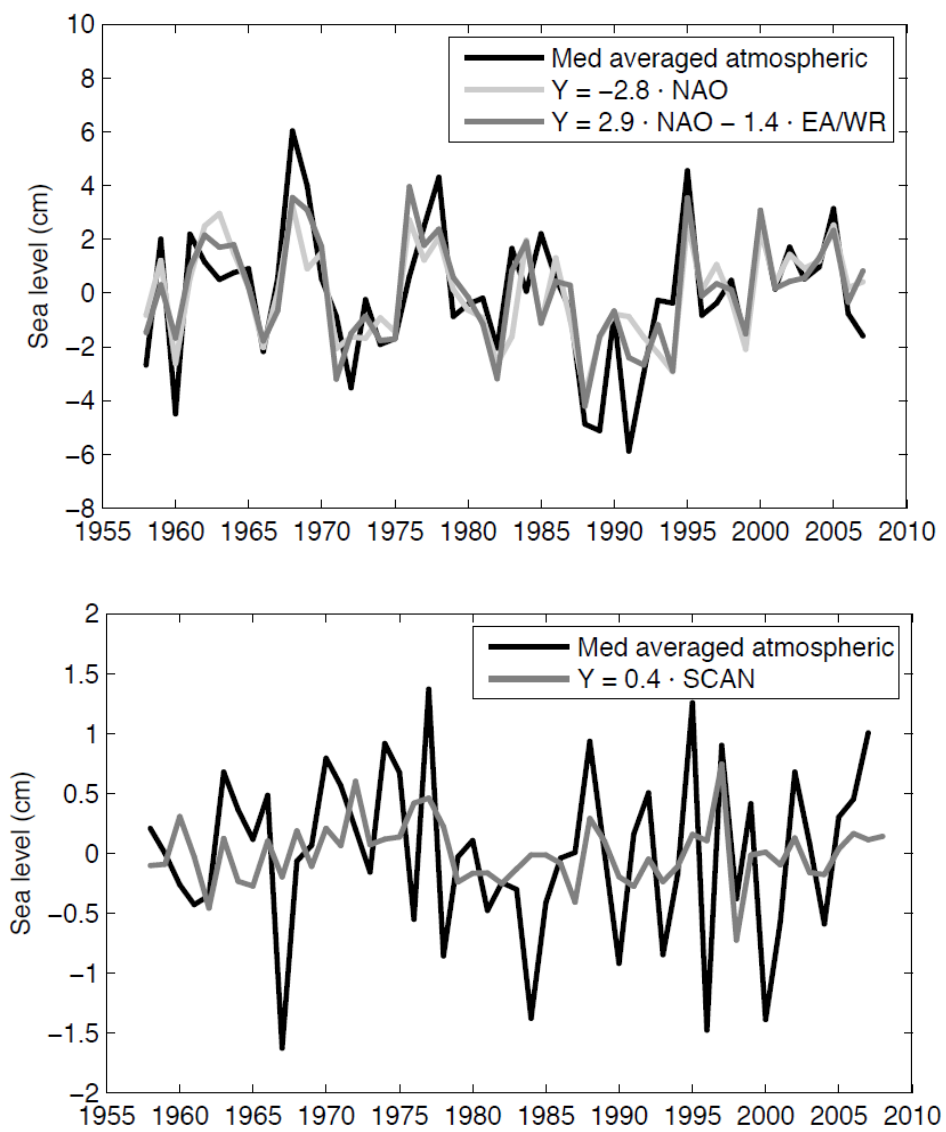
898 Figure 8. Dec-Mar and Jun-Aug maps of correlation coefficients between the climate 899 indices and the thermosteric sea level (left) and the rate of change of thermosteric sea 900 level (center and right) for the period 1950-2011. Dotted areas denote significant 901 correlation at $95 \%$ level.

a) Winter NAO - Therm

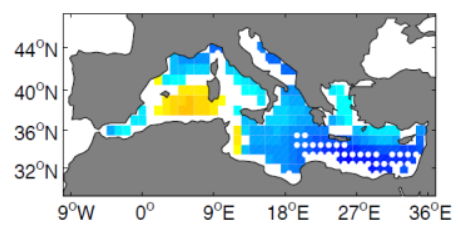

d) Winter EA - Therm

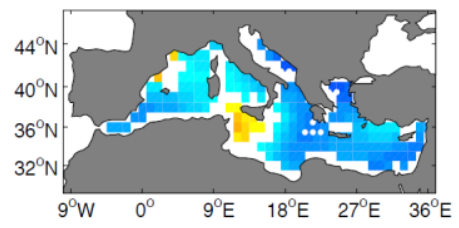

g) Winter EA/WR - Therm

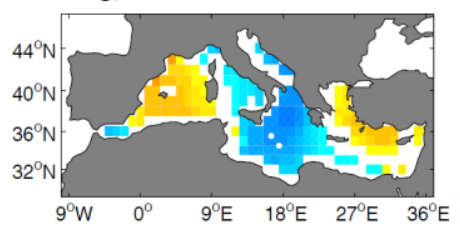

j) Winter SCAN - Therm

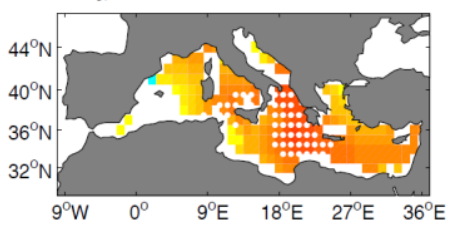

b) Winter NAO - Rate of change therm

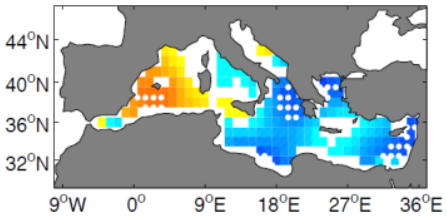

e) Winter EA - Rate of change therm

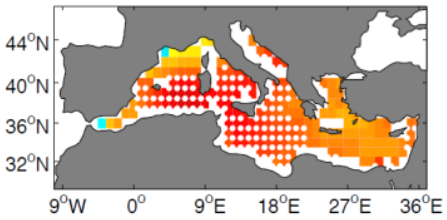

Winter EAMR - Rate of change therm

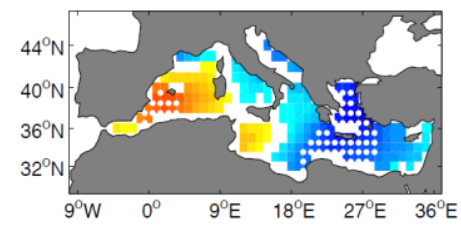

k) Winter SCAN- Rate of change therm I) Summer SCAN - Rate of change therm
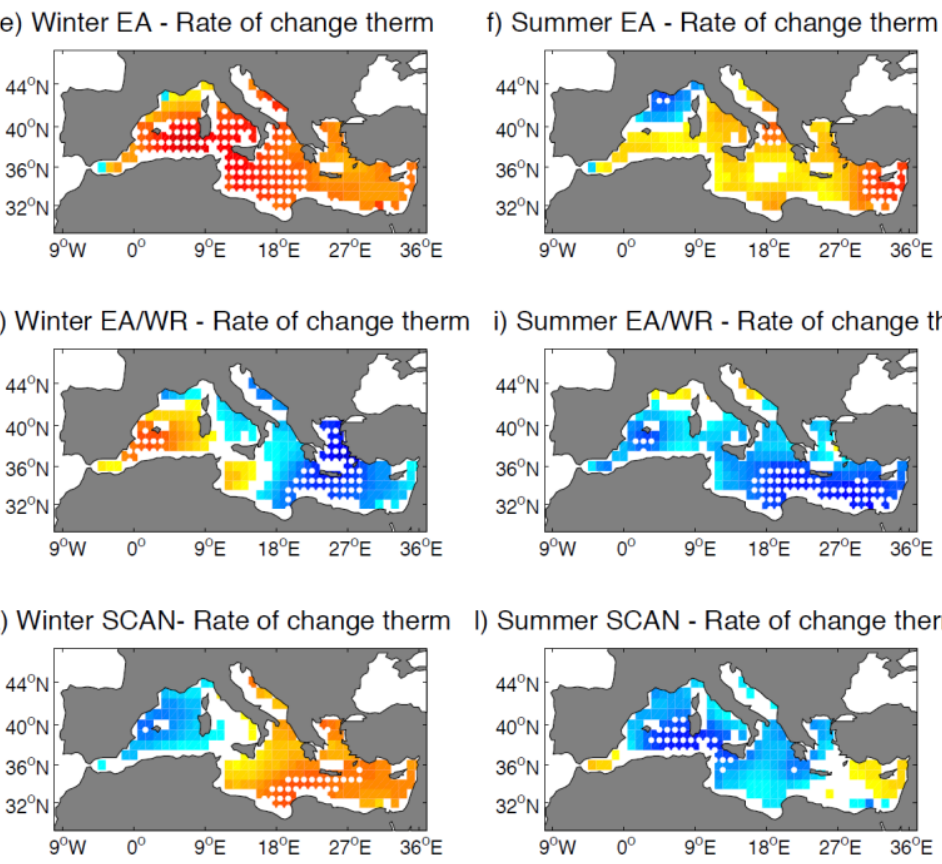

i) Summer EA/WR - Rate of change therm

903

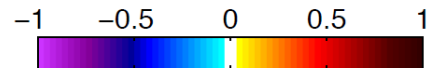

904

905

906

907

908

909 
912 Figure 9. Dec-Mar contribution of the SCAN to the winter basin averaged

913 thermosteric sea level. Averaged thermosteric sea level of the highest correlated

914 area is also shown for comparison (light-grey line).

915

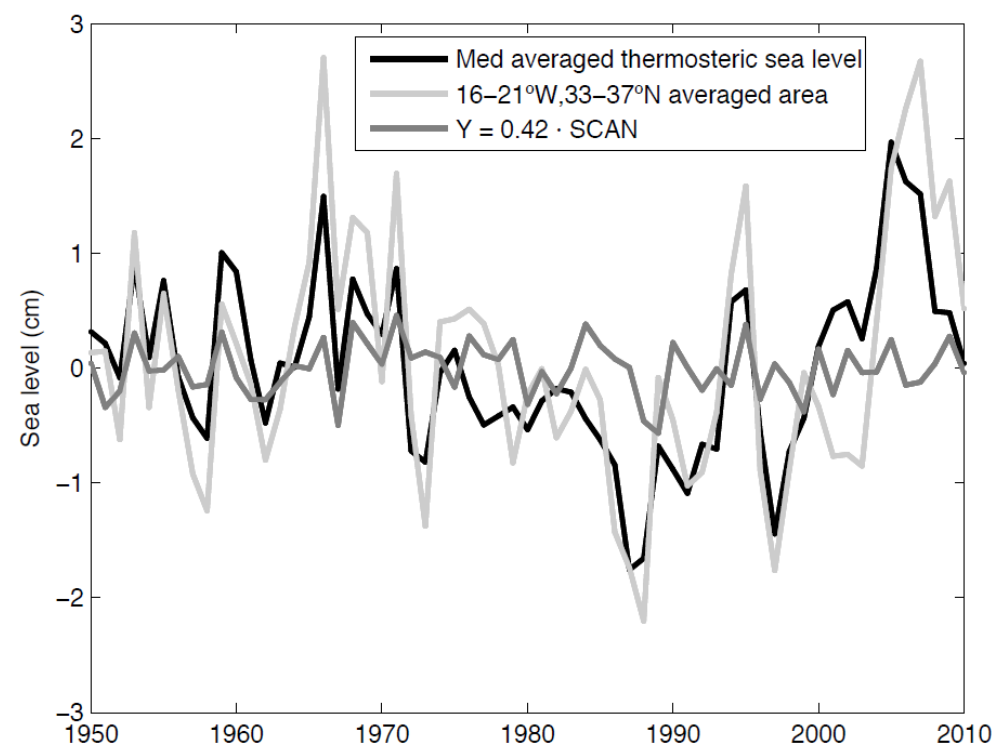


934 Figure 10. Winter (Dec-Mar) atmospherically-induced sea level $(\mathrm{cm})$ and $10 \mathrm{~m}$ wind 935 speed (vectors) averaged for a winter NAO (top) and EA/WR (bottom) indices: (a,c) 936 positive state, $(\mathrm{b}, \mathrm{d})$ negative state. Corresponding averaged sea level pressures are 937 contoured in intervals of $1 \mathrm{mb}$. Note that the horizontal vector (red arrow) is for scale and 938 indicates a wind speed of $2 \mathrm{~m} / \mathrm{s}$.

939

a) Positive NAO

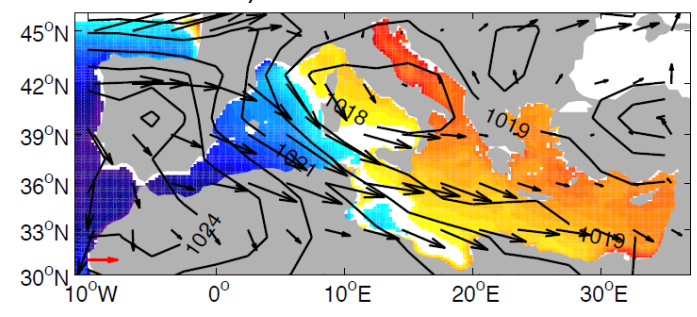

c) Positive EA/WR

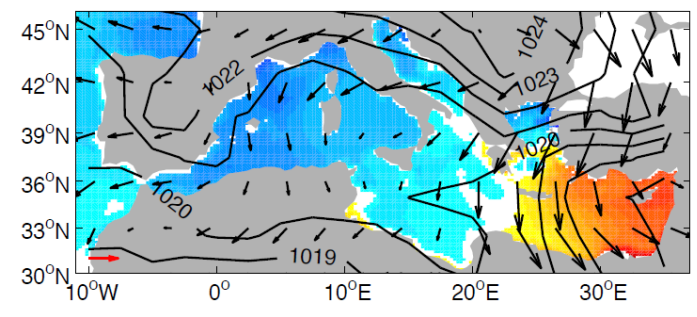

b) Negative NAO

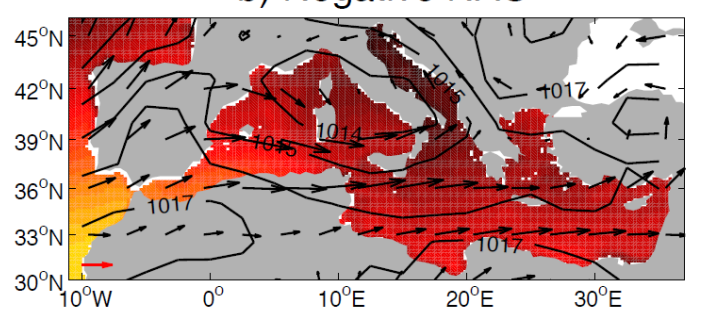

d) Negative EA/WR

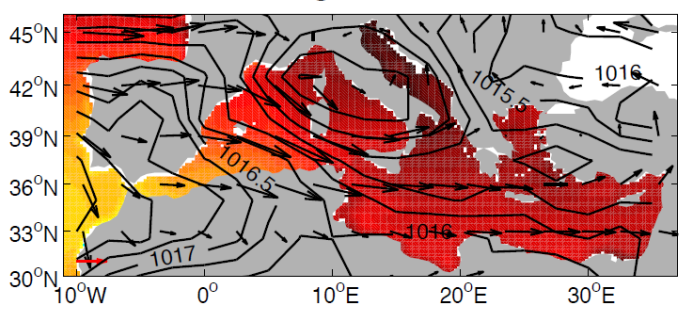

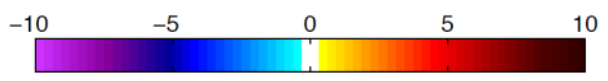


955 Figure 11. Winter (Dec-Mar) rate of change of thermosteric sea level anomalies $(\mathrm{cm})$ 956 and 10m wind speed (vectors) averaged for winter NAO (a,b), EA (c,d), EA/WR (e,f) 957 and $\operatorname{SCAN}(\mathrm{g}, \mathrm{h})$ indices under a positive state (left) and a negative state (right). 958 Corresponding averaged sea level pressures are contoured in intervals of $1 \mathrm{mb}$. Note that 959 the horizontal vector (red arrow) is for scale and indicates a wind speed of $2 \mathrm{~m} / \mathrm{s}$.

a) Positive NAO

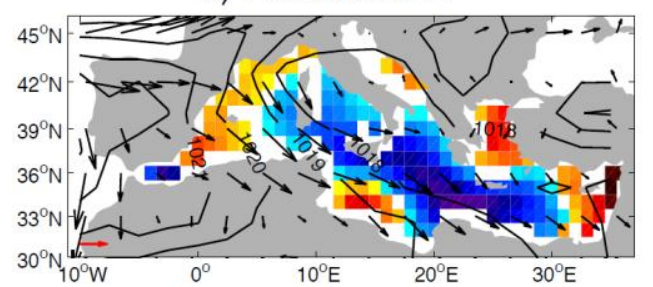

c) Positive EA

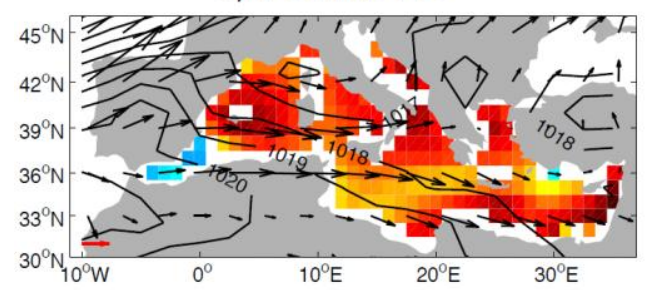

e) Positive EA/WR

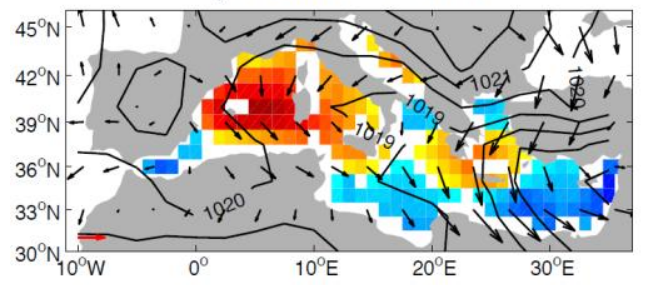

g) Positive SCAN

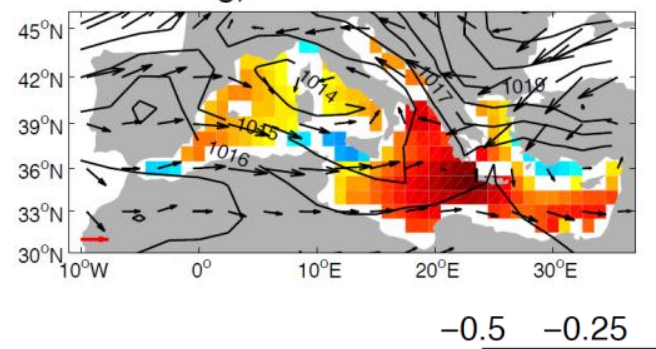

b) Negative NAO

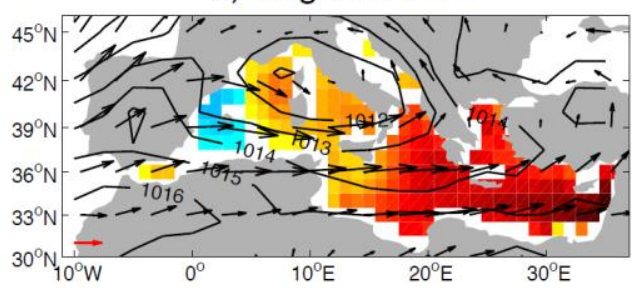

d) Negative EA

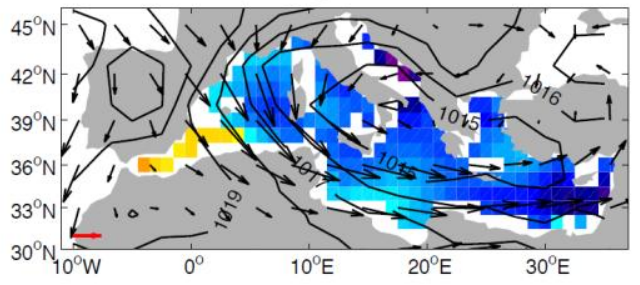

f) Negative EA/WR

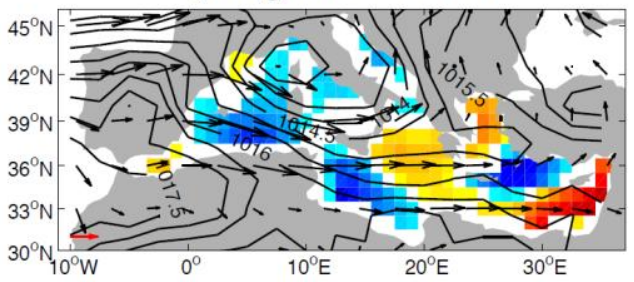

h) Negative SCAN

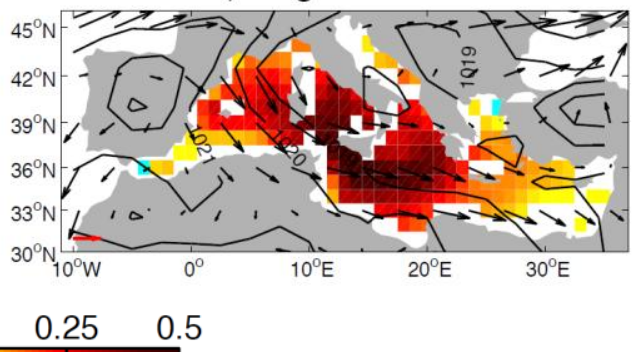


966 Figure 12. Summer (Jun-Aug) atmospherically induced sea level $(\mathrm{cm})$ averaged for a 967 summer SCAN positive and negative phases (above). Rate of change of thermosteric sea 968 level anomalies $(\mathrm{cm})$ averaged for a summer EA/WR positive and negative phases 969 (below). Corresponding 10m wind speed (vectors) and sea level pressure are contoured 970 in intervals of $1 \mathrm{mb}$. Note that the horizontal vector above Figure 12a is for scale and 971 indicates a wind speed of $2 \mathrm{~m} / \mathrm{s}$.

972

973

b) Negative SCAN

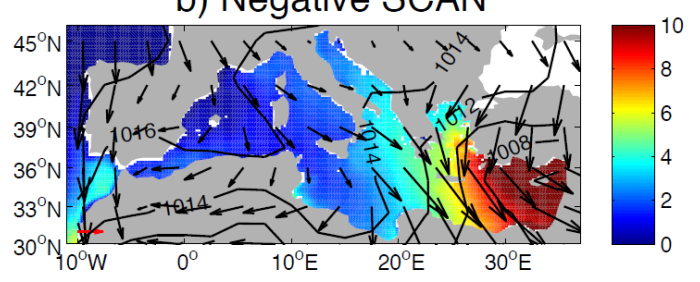

d) Negative EA/WR

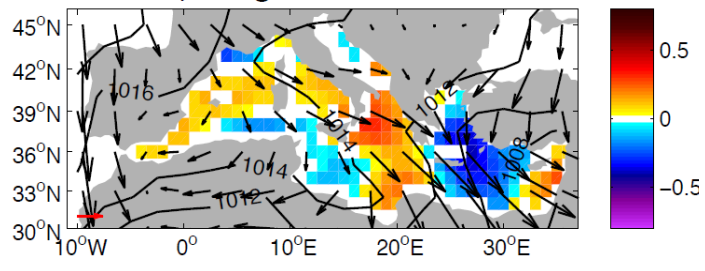

974 a) Positive SCAN

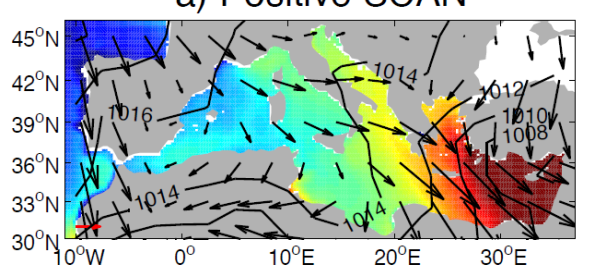

c) Positive EA/WR
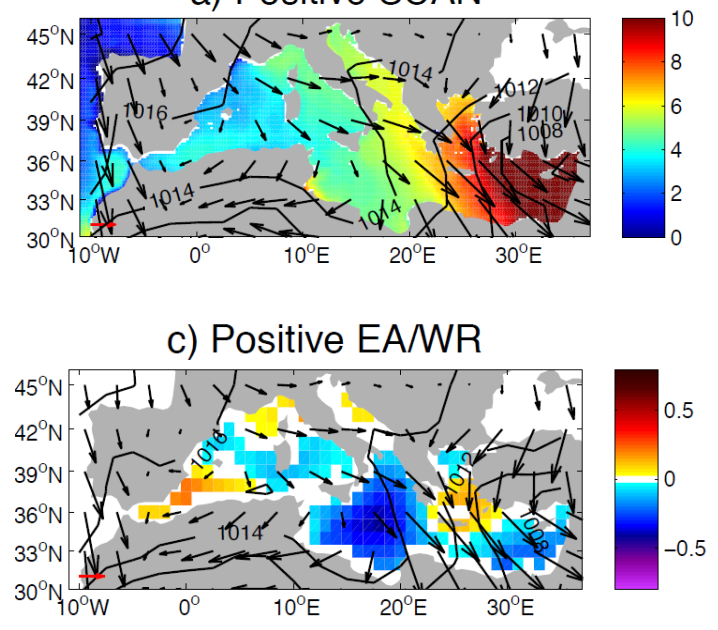

976

977

978

979

980 